\title{
Psychological Impediments to Mediation Success: Theory and Practice
}

\author{
RUSSELL KOROBKIN*
}

In the last two decades, much has been written on the causes of negotiation failure in litigation. This literature primarily comes from two methodological perspectives. The first perspective is based on social science research. Scholarship in economics and its offshoot, game theory, uses rationalist behavioral assumptions to construct models of negotiation behavior. Scholarship in psychology and related disciplines (including experimental economics) relies on experimental research that empirically investigates behavior in controlled, laboratory settings. Social science research in both of these scholarly traditions has the advantage of isolating individual variables and studying how each can affect settlement negotiation. The disadvantage of these approaches is that they always raise the question of "external validity"-that is, economic models are only as valid as the behavioral assumptions embedded within them, and behavior empirically documented in a particular laboratory setting may or may not occur in the highly contextual, real world circumstances of interest to lawyers and other dispute resolution practitioners.

A second, more practice-oriented body of literature relies on actual experience in settlement negotiation and mediation on the part of lawyers and mediators. The advantage of this perspective is that it draws insights from real-life experience of the type in which lawyers and mediators are actually interested, rather than abstractions created in laboratories. The disadvantage is that the unscientific nature of what are usually anecdotal accounts can suffer from reliability or representativeness problems. By "reliability" problems, I mean that the observations of a particular author might be idiosyncratic, biased, or otherwise different from observations that a different author might have made in those same situations. By "representativeness" problems, I mean that a small number of anecdotes might be idiosyncratic and their lessons not broadly generalizable.

In this article, I combine elements of these two perspectives, drawing on relevant experimental research-some conducted by myself, much conducted by others-and my personal experience as a mediator. ${ }^{1}$ My goal is to base

* Professor of Law, UCLA. An early version of this article was delivered as the Schwartz Lecture on Dispute Resolution at the Ohio State University Moritz College of Law on September 23, 2004.

${ }^{1}$ Drawing on my mediation experience in this context is complicated by the fact that mediating parties have a right to, and an expectation of, confidentiality concerning what 
the analysis on a body of scientific evidence that is confirmed, shaped, and extended by practical experience in the real world of dispute resolution. Parts I-IV will consider, in turn, four categories of psychological biases that can impede mediation success: optimistic overconfidence, attribution biases, framing effects, and reactive devaluation. Each of these parts will attempt to describe and substantiate the existence of a particular problem and to suggest prescriptions for mediators to mitigate the problem. ${ }^{2}$ The four biases considered do not comprise a complete list of psychological impediments to mediation success, but they are the ones that have been most salient in my mediation experience. ${ }^{3}$ Part $\mathrm{V}$ argues that the four primary types of psychological biases also can create a second-order impediment to mediation success by undermining disputant perceptions of interactional justice, potentially multiplying the hazards that the first-order biases create. The article concludes with a brief discussion of an implicit normative view about the proper role of mediators that underlies the article's descriptive and prescriptive elements.

Because my primary claim is that certain psychological biases impede mediation success, before proceeding it is necessary to define "success" in this context. My definition of success flows logically from the following normative standard: disputes should settle in mediation if there are one or more sets of agreement terms that both parties would prefer to accept rather than try the case to an adjudicated conclusion if the parties had an accurate and unbiased perception of the facts underlying the dispute, the legal risks, and the differential transaction and reputational cost involved in the case.

This standard has two critical components: First, it recognizes litigants' subjective preferences as legitimate. Even if a disputant's preferences are eccentric or unusual, the mediator should respect them. Second, it requires that, to be legitimate, disputant preferences and the decisions that follow

goes on in the mediation. To protect privacy and confidentiality, when I describe particular mediation experiences, I will modify some facts not relevant to the specific point being made. All of the anecdotes discussed should be understood to be generally, but not precisely, accurate.

2 It also bears noting briefly that, of course, psychological biases are not the only impediments to mediation success. A more complete analysis would have to consider, at a minimum, informational deficits, strategic behavior, and agency costs.

${ }^{3} \mathrm{My}$ mediation experience has been primarily in contract and tort cases in which the parties have little interest in preserving ongoing relationships with one another and are represented by attomeys in the mediation. The psychological biases that are familiar in my experience are not necessarily the ones that are most prevalent in mediations concerning different types of disputes. 
from them must be based on an objectively accurate view of reality. ${ }^{4}$ In other words, this standard implies that whether a particular dispute should settle in mediation or not might reasonably depend on how risk averse the parties are, how much they value a judicial pronouncement of fault for liability, and the value they put on repairing their damaged relationship with the other partyto use just a few examples-but should not depend on mistaken or biased perceptions of facts in the world.

My operative definition of mediation success derives from this standard. If the standard is satisfied, then mediation success is defined as a settlement ending the dispute; alternatively, if the standard is not satisfied-that is, there is no agreement that the well-informed and unbiased disputants would both prefer to adjudication-then mediation success is defined as an impasse rather than a settlement.

A logical implication of this definition of mediation success is that, if the standard is satisfied, a responsible mediator should try to overcome any impediments to settlement, but, if the standard is not satisfied, a mediator should not use his leverage to urge settlement. This is hardly an uncontroversial proposition. In fact, it is subject to attack from two opposing directions. "Dovish" mediation theorists believe that a mediator should not take as active a role in urging parties to settle as I will suggest. More "hawkish" mediators define "success" as settlement under nearly any circumstance short of legally actionable duress. This view of mediation is rarely endorsed in the scholarly literature, but in practice many mediatorsperhaps even most-fall into this group, pushing settlement regardless of context or circumstances. Defending my definition of success and its implications for the proper scope of mediation behavior, however, is beyond the scope of this article; I will proceed with my analysis under the assumption that the definition and its behavioral implications are accepted as given.

${ }^{4}$ Deconstructionists might argue that there is no such thing as an accurate view of reality, but I assume for the purposes of this article that (1) there are objective facts about the actions that lead to a dispute, about the dispute itself, and about the parties and their behavior, and (2) it is possible for the parties to either know these facts or make reasonable estimations of them given available information. 


\section{OPTIMISTIC OVERCONFIDENCE}

\section{A. The Social Scientific Basis of Optimistic Overconfidence}

Hundreds of research studies demonstrate that, on average, people are often overconfident in their predictions concerning the outcome of future events. A recent review calls this "[a]mong the most robust findings in research on social perceptions and cognitions over the last two decades." 5 Another calls it "[o]ne of the most robust findings in the psychology of prediction." them are better than they are in reality, and that the chances of bad things happening to them are worse than they are in reality. This effect has been demonstrated in the literature by different methodologies, two of which I will emphasize here.

In one type of study, subjects who are members of a particular group make predictions concerning the outcomes of future events that they will experience relative to other members of the group. A majority of subjectsoften quite a large majority-predict outcomes that are significantly above the median. For example, college students think that their income upon graduating from college will be higher than average, ${ }^{7}$ that they will enjoy their post-graduation job more than average, and that they will be more likely than average to have their work recognized with an award. ${ }^{8}$ Most adults believe that they are less likely than the average person their age to suffer from a variety of health problems later in life. ${ }^{9}$ One oft-cited study found that the subjects about to be married who were asked to estimate their likelihood of later divorcing provided a modal response of zero percent, even though most members of the group were aware that the rate of divorce in the general

${ }^{5}$ Marie Helweg-Larsen \& James A. Shepperd, Do Moderators of the Optimistic Bias Affect Personal or Target Risk Estimates? A Review of the Literature, 5 PERSONALITY \& SOC. PSYCHOL. REV. 74, 74 (2001).

${ }^{6}$ David A. Armour \& Shelley E. Taylor, When Predictions Fail: The Dilemma of Unrealistic Optimism, in HeURISTICS AND BIASES: THE PSYCHOLOGY OF INTUITIVE JUDGMENT 334, 334 (Thomas Gilovich et al. eds., 2002).

${ }^{7}$ Hamish G. W. Seaward \& Simon Kemp, Optimism Bias and Student Debt, 29 N.Z. J. PSYCHOL. 17, 18 (2000).

${ }^{8}$ Neil D. Weinstein, Unrealistic Optimism About Future Life Events, 39 J. PERSONALITY \& SOC. PSYCHOL. 806, 810 tbl.1 (1980).

${ }^{9}$ Neil D. Weinstein, Unrealistic Optimism About Susceptibility to Health Problems: Conclusions from a Community-Wide Sample, 10 J. BEHAV. MED. 481, 488 (1987). 
population is between forty and fifty percent. ${ }^{10} \mathrm{~A}$ recent study that surveyed subjects on a variety of different future events concluded that, on average, eighty-five to ninety percent of people think that the future will be more pleasant and less painful for them than for the average person. ${ }^{11}$ This typical result logically implies that at least some of the subjects are overconfident, but, importantly, it does not suggest that all of the subjects necessarily are overconfident.

Other studies test estimations that people make about past events or predictions that people make about not-too-distant future events against the actual outcomes and document overconfidence directly. So, for example, one study found that subjects overestimated the amount of housework that they did and their contribution to a group discussion. ${ }^{12}$ Others found that students expect higher exam grades on average than they actually received, ${ }^{13} \mathrm{MBA}$ students expected more job offers and higher average salary offers when they graduated from business school than they actually received, ${ }^{14}$ financial analysts overestimated corporate earnings, ${ }^{15}$ and venture capitalists were overconfident in their estimations of how likely potential ventures were to succeed. ${ }^{16}$

Why are people, on average, overconfident in their prediction of future events? There are likely at least two explanations. The first is that people pay differential attention to positive and negative facts. That is, people tend to place more emphasis on facts that are consistent with desired outcomes than facts that are inconsistent with desired outcomes. Consider, for example, one very famous study from the 1950's. Dartmouth and Princeton students

${ }^{10}$ See Lynn A. Baker \& Robert E. Emery, When Every Relationship is Above Average: Perceptions and Expectations of Divorce at the Time of Marriage, 17 L. \& HuM. BEHAV. 439, 443 (1993); see also Weinstein, supra note 8, at 810 tbl.1.

11 Armour \& Taylor, supra note 6, at 336 (reporting general results of unpublished studies).

12 Michael Ross \& Fiore Sicoly, Egocentric Biases in Availability and Attribution, 37 J. PERSONALITY \& SOC. PSYCHOL. 322, 325-26, 330-31, 334-35 (1979).

${ }^{13}$ Paul W. Grimes, The Overconfident Principles of Economics Student: An Examination of a Metacognitive Skill, 33 J. ECON. EDUC. 15, 21 (2002).

14 Stephen J. Hoch, Counterfactual Reasoning and Accuracy in Predicting Personal Events, 11 J. EXPERIMENTAL PSYCHOL.: LEARNING, MEMORY \& COGNITION 719, 722-23, tbl.1 (1985).

15 Thomas G. Calderon, Predictive Properties of Analysts' Forecasts of Corporate Earnings, 29 MID-ATLANTIC J. BuS. 41, 57 (1993).

${ }^{16}$ Andrew L. Zacharakis \& Dean A. Shepherd, The Nature of Information and Overconfidence on Venture Capitalists' Decision Making, 16 J. BUS. VENTURING 311 , 311-12 (2001). 
viewed film of a controversial football game between the two schools, after which the Dartmouth team was accused of dirty play. ${ }^{17}$ The student subjects were asked to judge how many infractions were committed during the game by the two teams. ${ }^{18}$ Princeton fans recorded that Dartmouth committed more than twice as many penalties as Princeton, while Dartmouth students believed the teams committed about the same number of penalties. ${ }^{19}$ In a more recent experiment, students with pro- and anti-death penalty views were given two empirical studies of the death penalty, one of which supported the claim that the death penalty has a deterrent effect and one of which contradicted that claim. ${ }^{20}$ Proponents of the death penalty judged the pro-deterrence study to be more convincing, while opponents registered the opposite opinion. ${ }^{21}$ After viewing the two studies, the proponents reported that they were even more in favor of the death penalty, while opponents reported that they were even more opposed. ${ }^{22}$

In a study placed in the litigation context, experimenters gave subjects an identical set of facts about a lawsuit but told half the subjects that they would play the role of the plaintiff in a negotiation simulation and told the other half of the subjects that they would play the role of the defendant. ${ }^{23}$ Following the actual simulation, subjects were asked to recall and write down facts about the case that favored their position and facts about the case that favored the opposing position. ${ }^{24}$ When doing so, they recalled significantly more facts favoring their own position than facts that supported the opposing position. ${ }^{25}$ In a similar study in the context of a collective bargaining negotiation, subjects similarly demonstrated biased recall, recalling more facts that supported their position than the other side's position. ${ }^{26}$ Taken together, these experiments suggest that people often differentially attend to and

17 Albert H. Hastorf \& Hadley Cantril, They Saw a Game: A Case Study, 49 J. ABNORMAL \& SOC. PSYCHOL. 129, 130-32 (1954).

18 Id.

19 Id.

${ }^{20}$ Charles G. Lord et al., Biased Assimilation and Attitude Polarization: The Effects of Prior Theories on Subsequently Considered Evidence, 37 J. PERSONALITY. \& SOC. PSYCHOL. 2098, 2098 (1979).

21 Id. at $2101-02$.

22 Id. at $2103-04$.

23 George Loewenstein et al., Self-Serving Assessments of Fairness and Pretrial Bargaining, 22 J. LEGAL STUD. 135, 146 (1993).

24 Id. at 148.

25 Id. at $150-51$.

${ }^{26}$ Leigh Thompson \& George Loewenstein, Egocentric Interpretations of Fairness and Interpersonal Conflict, 51 ORganizational BEHAV. \& HUM. DeCISION PROCESSES 176, 189-90 (1992). 
differentially recall facts based on whether or not those facts support their position or future prospects. This tendency might explain a recent finding that eighty-seven percent of magistrate judges believe that they are among the fifty percent of their peer group that are reversed by higher courts least often. ${ }^{27}$

A separate element of overconfidence appears to be the tendency of people to make self-serving assessments of their ability. For example, seventy percent of high school students in one study rated themselves above average in leadership skills, while only two percent ranked themselves below average on that dimension; sixty percent ranked themselves in the top ten percent in ability to get along with others. ${ }^{28}$ Ninety-four percent of college professors in a different study believed that they were above average at their jobs. ${ }^{29}$ Most drivers think that they are better-than-average drivers. ${ }^{30}$ Most taxi drivers think they are better than average taxi drivers, ${ }^{31}$ and nearly eighty percent of truck drivers think they are safer than the average truck driver. ${ }^{32}$ Most negotiators believe they are more fair than the average negotiator. ${ }^{33}$ Sometimes referred to as the "above-average effect," this phenomenon leads to the result that as perceived control over events and outcomes increases, so does the observed level of optimistic overconfidence. ${ }^{34}$

27 Chris Guthrie et al., Inside the Judicial Mind, 86 CORNELL L. REV. 777, 814 (2001).

28 See David Dunning et al., Ambiguity and Self-Evaluation: The Role of Idiosyncratic Trait Definitions in Self-Serving Assessments of Ability, in HEURISTICS AND BIASES: The PSYCHOLOGY OF INTUITIVE JudgMENT 324, 324 (Thomas Gilovich et al. eds., 2002).

${ }^{29} \mathrm{~K}$. Patricia Cross, Not Can, But Will College Teaching Be Improved?, in 17 New DiRECTIONS FOR HigHER EDUCATION 1, 10 (John A. Centra ed., 1977).

30 Ola Svenson, Are We All Less Risky and More Skillful Than Our Fellow Drivers, 47 ACTA PsYchologica 143, 146 (1981).

31 James R. Dalziel \& R.F. Soames Job, Motor Vehicle Accidents, Fatigue and Optimism Bias in Taxi Drivers, 29 ACCIDENT ANALYsIS \& PREVENTION 489, 493 (1997).

32 D. Walton, Examining the Self-Enhancement Bias: Professional Truck Drivers' Perceptions of Speed, Safety, Skill and Consideration, 2 TRANSP. RES. PART F 91, 99 (1999).

33 Roderick M. Kramer et al., Self-Enhancement Biases and Negotiator Judgment: Effects of Self-Esteem and Mood, 56 Organizational BeVAV. \& HuMAN Decision PROCESSES 110, 124 (1993); Leigh Thompson \& Reid Hastie, Judgment Tasks and Biases in Negotiation, in 2 RESEARCH ON NEGOTIATION IN ORGANIZATIONS 31, 43 (Blair H. Sheppard et al. eds., 1990).

34 Helweg-Larsen \& Shepperd, supra note 5, at 85-86. 
A related and more troubling finding, called the "illusion of control,"35 is that people not only think that they are better than average when skill or ability is relevant to outcomes, they sometimes believe that they have more control over outcomes than they do. For example, one study found that subjects demanded substantially more money to sell a lottery ticket prior to the lottery and were significantly less likely to trade the ticket for one in a lottery with better odds if they had chosen the ticket than if they were randomly assigned a ticket. ${ }^{36}$ Why people often believe they have more agency than they actually do is a complicated question, but theorists from a variety of disciplines have hypothesized that feelings of control are necessary for emotional health. ${ }^{37}$ Whatever the source, when people overestimate their control over a situation, a logical consequence is a tendency toward optimistically overconfident predictions of desirable outcomes.

\section{B. Overconfidence as an Impediment to Mediation Success}

The problem caused by optimistic overconfidence in the mediation setting is not difficult to understand. Although plaintiffs dismiss some lawsuits after they are filed, most parties that come to mediation view adjudication as their alternative to settlement. As a consequence, the predictions of the parties or of their lawyers concerning the likely outcome of adjudication is usually the most important factor in determining the disputants' reservation prices: that is, the maximum sum the defendant would be willing to pay to settle the case and the minimum sum that the plaintiff would be willing to accept in order to settle out of court. ${ }^{38}$ If the disputants have similar predictions concerning the likely outcome of litigation, the case usually will settle because the costs and risks that come with adjudication cause most litigants to prefer a mediated settlement to a litigation "lottery ticket" with the same, or even a somewhat lower, expected monetary value. If one or both parties substantially overestimate their chances of prevailing in litigation, however, the calculation changes. Litigation looks relatively more desirable to the overconfident disputant, and the result can be that there are

35 See generally Ellen J. Langer, The Illusion of Control, 32 J. PERSONALITY \& SOC. PSYCHOL. 311 (1975).

$36 \mathrm{Id}$. at $316-18$.

37 See, e.g., Michael W. Morris et al., Time of Decision, Ethical Obligation, and Causal Illusion, in NEGOTIATION AS A SOCIAL PROCESS 209, 232 (Roderick M. Kramer \& David M. Messick eds., 1995) (discussing the evolution of causal illusions).

38 See Russell Korobkin, A Positive Theory of Legal Negotiation, 88 GEO. L.J. 1789, 1792-93 (2000). 
no possible settlements that both parties would rate as better for them than taking the matter to court.

In the simplest of disputes involving only a single legal or factual issue, optimistic overconfidence can cause the parties to disagree over the likely resolution of that issue by a court, making impasse in mediation likely. In one simple tort case that I mediated, for example, the defendant's action admittedly caused harm to the plaintiff, and the only issue was whether the defendant's action was negligent. The defendant's attorney said he was extremely confident in his ability to prevail in court, predicting a ninety percent likelihood of success. The plaintiff's attorney conceded that his case was not "a sure thing," but predicted a seventy percent likelihood of success. As a consequence of these predictions, the defendant's reservation price for settlement was extremely low, and the plaintiff's relatively high.

In other cases, where multiple issues are in dispute, the impediment of optimistic overconfidence concerning a particular issue can be multiplied in its effect if parties differentially focus their attention on their strongest issues and under-appreciate the issues on which their position is weaker. Consider, as an example, the following dispute that I mediated, in which the plaintiff alleged a variety of breach of contract and tort claims. The defendant's attorney believed that the suit was duplicative of an earlier lawsuit brought by the same plaintiff in which the defendant had prevailed. She believed that her client would prevail in a motion to dismiss on the ground of res judicata and was even more confident in her ability to prevail at trial on the merits even if she lost the motion. The plaintiff, for his part, was convinced that the claims, while involving the same two parties, were completely distinct, and that a judge would so conclude. Although I believed that the defendant was likely to prevail on the substantive merits of the dispute, I agreed with the plaintiff that his claims were not duplicative of earlier litigation and were, therefore, likely to survive the defendant's motion to dismiss. Because of the defendant's confidence in and focus on the merits of his case, the defendant, in my opinion, undervalued the expected transaction costs of continuing with litigation rather than settling the case: a loss on the motion to dismiss would mean expensive discovery and trial preparation, even if he were ultimately to prevail. Consequently, the defendant was unwilling to offer more than a token amount of money to settle the dispute. On the other hand, the plaintiff's confidence in his ability to survive the motion (justified, in my estimation) caused him to focus too much attention on the motion and pay too little attention to the proof problems he faced on the merits on the dispute. The result was an overall level of confidence in ultimate success that was (again, in my estimation) unjustified, and translated into a high reservation price for settlement. 
In my judgment, optimistic overconfidence is the most significant psychological impediment to settlement in the mediation context. This bold claim must be immediately qualified, however, with the observation that validating it empirically would be quite difficult. Testing the overconfidence hypothesis would be a relatively straightforward matter if mediators could rely on both disputants to be completely honest and forthcoming: Mediators simply could ask each party how likely he believes he is to prevail if mediation fails and the case is resolved through adjudication and add together the two responses. If the sum of the responses exceeds one hundred percent, this reveals that one or both parties are overconfident about their chances of success, because the chance of plaintiff success plus the chance of defendant success logically equals that amount.

The problem, of course, is that there are reasons why disputants and their attorneys are often-perhaps even usually - unlikely to be completely honest with the mediator who probes for such information, even in a private caucus. Parties wish to convince the mediator to exert leverage on their opponent to make concessions, and this goal is best achieved by convincing the mediator that they will demand a high price (or will pay only a low price) to settle. Convincing the mediator of the sincerity of such claims, in turn, depends in large part on a party's ability to credibly overstate the extent to which he really thinks he is likely to prevail in litigation.

In addition, the agency relationship between lawyer and client provides lawyers with a personal incentive to overstate their true level of confidence in the merits of their client's case. A lawyer often wants to project confidence to impress the client that he empathizes with the client's circumstances and believes in both the justice and viability of the client's claim. This is probably good public relations; who wants to hire an unsupportive or skeptical lawyer ${ }^{39}$ But the result can be that the lawyer feels obliged to express more confidence in the strength of the client's legal position than he actually has.

Simply put, when two lawyers each tell the mediator they believe that they have a 90 percent likelihood of prevailing at trial, it is quite possibleprobably even likely-that one or both is lying about his actual estimation of success in an effort to "spin" the mediator, his client, or both. In such a situation, it is impossible to know for sure whether the sum of their actual estimates of success exceed 100 percent and thereby confirm that optimistic

39 Cf. Donald C. Langevoort, Ego, Human Behavior, and Law, 81 VA. L. REV. 853, 861 (1995) (predicting clients will respond favorably to overconfident lawyers); Richard Birke \& Craig R. Fox, Psychological Principles in Negotiating Civil Settlements, 4 HARV. NEGOT. L. REV. 1, 20 (1999) ("Many clients want to be represented by a counselor brimming with confidence."). 
overconfidence is an impediment to mediation success in that particular dispute.

Notwithstanding these reasons for suspecting that expressed overconfidence will often be feigned, experimental evidence suggests that at least a portion of the overconfidence displayed in mediation is real, rather than just strategic posturing or bluster. In one important study; mentioned above, student subjects were given identical facts about a lawsuit, but half were told that they were going to play the role of the plaintiff and half that they were going to play the role of the defendant. The experimenters then asked the subjects to privately estimate how much money a judge was likely to award the plaintiff in the case. ${ }^{40}$ In this experimental setting, in which the subjects had no strategic reason to overstate their actual level of confidence-subjects knew that no one other than the experimenter would see their estimates - the plaintiff subjects estimated the judge would award the plaintiff substantially more money than the defendant subjects estimated. ${ }^{41}$ Another study found that negotiators systematically overestimate their likely success in final offer arbitration, in which each party submits a recommended award and the arbitrator must resolve the dispute by choosing between the two. ${ }^{42} \mathrm{~A}$ third found that subjects randomly assigned to the role of either management or union in a labor negotiation simulation tended to believe that a fair wage from a neutral perspective was one disproportionately favorable to their side. ${ }^{43}$

Two observations about the actual practice of mediation, as distinguished from the controlled laboratory setting in which the experimental results are elicited, could undermine the hypothesis that overconfidence is a significant problem in mediation. For reasons discussed below, however, neither of these observations creates a persuasive challenge to my overconfidence-asimpediment hypothesis.

One obvious difference between the mediation context and the typical conditions of laboratory experiments is the presence of lawyers as intermediaries in many (but not all) mediation situations. One might suspect that, even assuming overconfidence on the part of disputants, lawyers should

40 Loewenstein et al., supra note 23, at 146.

41 Id. at 150.

42 Margaret A. Neale \& Max H. Bazerman, The Role of Perspective-Taking Ability in Negotiating Under Different Forms of Arbitration, 36 INDUS. \& LAB. REL. REV. 378 (1983).

43 Thompson \& Loewenstein, supra note 26 , at 183-84. 
be able to mitigate, if not eliminate, the bias. ${ }^{44}$ Lawyers are repeat performers at the task of evaluating case strength, and many have experienced the negative consequences of overly positive predictions (i.e., suffered courtroom defeats), a factor which can temper optimistic overconfidence. ${ }^{45}$ And litigants will usually believe their lawyer is more expert than they are at evaluating the strength of their legal position and defer to counsel's judgment on this question. There is little doubt that many lawyers successfully serve the function of mitigating optimistic overconfidence, dampening their clients' initial zest for litigation with a healthy dose of reality. It is unlikely, however, that all lawyers are able to play this role consistently, for two reasons explained below.

First, research suggest that even parties with no stake in a dispute will tend to overweight evidence to which their attention is drawn. In one study, subjects were provided a set of basic facts about a litigation matter and then exposed either to arguments favoring the plaintiff or the defendant. ${ }^{46}$ Subjects presented with the pro-plaintiff arguments predicted the likelihood of a plaintiff's verdict was higher than subjects presented with the prodefendant arguments predicted ${ }^{47}$ Importantly, all subjects knew that they were only seeing half the arguments - specifically, the subjects viewing the pro-plaintiff arguments were told that the defendant had a similar number of arguments, but they were being shown only those of the plaintiff. ${ }^{48}$ Lawyers, of course, are likely to differentially focus their attention on arguments that favor their client, as opposed to arguments that favor the adversary, when they are preparing the case for mediation and potential litigation. Thus, although lawyers are usually more emotionally distant from disputes than their clients, the better hypothesis is that they will still tend to pay more attention to facts that support their position than facts that undermine it, and

${ }^{44}$ In fact, Chris Guthrie and I have conducted experiments that found lawyers playing the role of lawyers in settlement negotiation simulations were not susceptible to other psychological biases that did appear to affect students playing the role of litigants in those same simulations. See Russell Korobkin \& Chris Guthrie, Psychology, Economics, and Settlement: A New Look at the Role of the Lawyer, 76 TEX. L. REV. 77, 95-112 (1997).

45 See Hal R. Arkes et al., Two Methods of Reducing Overconfidence, 39 Organizational Behav. \& HuM. Decision Processes 133, 136-38 (1987); HelwegLarson \& Shepperd, supra note 5, at 86-87.

46 Lyle A. Brenner et al., On the Evaluation of One-sided Evidence, 9 J. BEHAV. Decision MAKING 59, 61-62 (1996); see also Daniel Kahneman \& Amos Tversky, Conflict Resolution: A Cognitive Perspective, in BARRIERS TO CONFLICT RESOLUTION 45, 46 (Kenneth J. Arrow et al. eds., 1995).

${ }^{47}$ Brenner et al., supra note 46 , at 62-64.

48 Id. at $61-62$. 
that this will lead to overconfidence, on average. ${ }^{49}$ It seems unlikely that this tendency will be tempered by experience, even for lawyers who have handled a significant number of cases through adjudication, because no two cases are precisely alike and because a courtroom setback is not itself evidence that that even a rosy prediction ex ante was unduly optimistic.

Second, lawyers will actually perform in the courtroom if settlement efforts fail, suggesting that self-serving assessments of their advocacy ability could lead them to overvalue cases, on average. That is, a lawyer's prediction about his client's odds in court is not merely an evaluation of a set of static facts but is also, in part, an evaluation of the lawyer's skill. The empirical evidence of optimistic overconfidence supports the prediction that, in this situation, lawyers will tend toward overconfidence in analyzing the litigation value of their client's causes of action. 50

A second basis for questioning the claim that overconfidence is a serious impediment to mediation success is that most cases do settle short of adjudication, whether or not they are mediated. Only a very small percentage of cases actually go to trial, and even when cases decided by trial are combined with cases resolved on motions, privately settled disputes far outnumber those resolved by courts. 51 One might contend that if overconfidence were a significant impediment to mediation success, we would expect that most cases would be resolved through adjudication rather than out-of-court settlement.

I believe this logic is faulty for at least two reasons. First, even if overconfidence prevents settlement in only a minority of mediated cases, this does not imply that the problem is not significant enough to warrant mediators' attention. Second, and more importantly, there is evidence that the extent of overconfidence is correlated with the temporal proximity of feedback; that is, when people know that their prediction is going to be evaluated as correct or incorrect, they tend to be more overconfident when the time of evaluation is distant and less so as the time of evaluation draws

49 See Langevoort, supra note 39, at 860-61 (predicting that "litigators are likely to develop a self-serving and inflated internal assessment of the likelihood that they will win their cases").

50 Note that the tendency for overconfidence in this situation, while suboptimal for evaluating the settlement value of a case, might be valuable when mediation fails and a trial ensues to the extent that excessive optimism could make the lawyer a more persuasive advocate. See Ward Farnsworth, The Legal Regulation of Self-Serving Bias, 37 U.C. DAVIS L. REV. 567, 576 (2003).

51 See Marc Galanter \& Mia Cahill, "Most Cases Settle": Judicial Promotion and Regulation of Settlements, 46 STAN. L. REV 1339, 1340 (1994). 
near. ${ }^{52}$ This could be because people become more careful in their analysis if evaluation is imminent or could result from increased anxiety associated with the evaluation that is interpreted as greater pessimism about the quality of the prediction. This feature of overconfidence suggests that even though most litigated disputes settle prior to adjudication, overconfidence might prevent cases that settle on the proverbial "courthouse steps," when the "feedback" of judge or jury looms, from settling during earlier mediation efforts. If this is in fact the case, optimistic overconfidence can result in needless delay, causing parties who will eventually settle out of court to bear the transaction costs (and emotional costs) associated with ongoing discovery and case preparation.

\section{Potential Interventions}

Optimistic overconfidence on the part of mediating parties or their lawyers calls for mediators to try to create objective, well-calibrated evaluations of the litigation prospects on the part of the parties. Three types of intervention can potentially serve this goal.

\section{Help Parties De-Bias Themselves}

The least invasive of the many potential interventions designed to mitigate the problem of optimistic overconfidence is for the mediator to explain the bias to the parties, in hopes that awareness of the general tendency will cause the parties to reassess their view of the merits of the case with greater objectively. One study provides some support for the hope that this might reduce overconfidence. Neale and Bazerman found that undergraduate students who had to submit a dispute to final offer arbitration were less confident about their chances of prevailing if they were told negotiators routinely overestimate their chances of success in such arbitrations than if they were not given this information. ${ }^{53}$ Most evidence, however, suggests that merely warning people about the tendency toward overconfidence accomplishes little. ${ }^{54}$ For example, one study found thatperhaps not surprisingly - people are optimistically overconfident about their

52 See Armour \& Taylor, supra note 6, at 339-40 (describing studies); HelwegLarsen \& Shepperd, supra note 5, at 84-85.

53 Margaret A. Neale \& Max H. Bazerman, The Effects of Framing and Negotiator Overconfidence on Bargaining Behaviors and Outcomes, 28 ACAD. MGMT. J. 34, 43 (1985).

54 See generally Baruch Fischhoff, Debiasing, in JUDGMENT UNDER UNCERTAINTY: HEURISTICS AND BIASES 422 (Daniel Kahneman et al. eds., 1982). 
ability to avoid suffering from the optimistic overconfidence bias. On a particular set of traits, experimental subjects rated themselves more positively than the average of their peer group eighty-seven percent of the time. ${ }^{55}$ When the basic contours of the optimistic overconfidence bias were then explained to the subjects, however, only twenty-four percent said that their responses were likely biased. ${ }^{56}$

My experience with lawyers in mediation is that, while they often find a description of the bias interesting and comment that it conforms with their perception of other lawyers' behavior, few are willing to concede that they themselves are less than objective in the analysis of their particular case. It is possible, however, that some lawyers respond to an explanation of optimistic overconfidence by tempering their confidence to some extent, even if they do not report that they are doing so.

Perhaps a better alternative is for the mediator to ask the parties in private caucus to discuss or enumerate the weaknesses of their case. Some studies have successfully reduced optimistic overconfidence by asking experimental subjects to list weaknesses associated with their position or enumerate reasons their answer to a question or prediction concerning a future event might be wrong. ${ }^{57} \mathrm{~A}$ related intervention is for the mediator to ask the parties' lawyers to present the argument that they believe the other side would be likely to advance in court. ${ }^{58}$

While these approaches have some promise, the interventions seem likely to be less effective when the audience is professional litigators than in

55 Emily Pronin et al., Understanding Misunderstanding: Social Psychological Perspectives, in HeURISTICS AND BIASES: THE PSYCHOLOGY OF INTUITIVE JUDGMENT 636, 660-62 (Thomas Gilovich et al. eds., 2002).

56 Id. at 662. See also James Fredrich, On Seeing Oneself as Less Self-Serving Than Others: The Ultimate Self-Serving Bias, 23 TEACHING PSYCHOL. 107, 108 (1996) (stating that people who learned about the overconfidence bias rated themselves as less susceptible to it than their average peer); $c f$. Linda Babcock \& George Loewenstein, Explaining Bargaining Impasse: The Role of Self-Serving Biases, 11 J. ECON. PERSP. 109, 115 (1997) (explaining the overconfidence bias to subjects in litigation negotiation experiment did not reduce the bias or increase observed rate of settlement).

57 See Linda Babcock et al., Creating Convergence: Debiasing Biased Litigants, 22 LAW \& SOC. INQUIRY 913, 918 (1998); Brenner et al., supra note 46, at 66-67; Hoch, supra note 14, at 727; Asher Koriat et al., Reasons for Confidence, 6 J. EXPERIMENTAL PSYCHOL.: HuM. LEARNING \& MEMORY 107 (1980). But see Neil D. Weinstein \& William M. Klein, Resistance of Personal Risk Perceptions to Debiasing Interventions, 14 HEALTH PSYCHOL. 132, 138 (1995) (finding "weak and inconsistent effects").

58 Some experimental evidence that presenting their opponents' position helps reduce the perceived distance between them and their opponents. See Pronin et al., supra note 55 , at 653 . 
non-mediation contexts, or even in mediations involving unrepresented parties. The primary problem is that litigators are fully aware that the their adversary will make contradictory arguments, have thought about what those arguments might be, and very often have identified the opposing side's best arguments in advance of the mediation. That is, asking a lawyer to identify weaknesses in his case is not likely to cause him to access ideas or information that he has not previously considered. Consequently, in my experience, when mediators ask lawyers to identify the weaknesses of their cases or identify their opponent's likely arguments, lawyers are able to do so quickly but are equally ready to provide a detailed account of why they would prevail in court despite those weaknesses. This lawyerly skill-no doubt honed in law school courses in which professors ask students to make arguments and anticipate counter arguments ${ }^{59}$ - suggests a tendency to identify undesirable facts and arguments for the purposes of generating responses rather than for the purpose of conducting an objective evaluation in a way that could substantially lessen the force of the overconfidence bias. Put another way, although non-lawyers asked to identify weaknesses in their position might generate new counterarguments and reassess the strength of their case, ${ }^{60}$ lawyers seem more likely both to have already identified potential weaknesses in their position and, when prompted with those weaknesses, to focus on refuting rather than reevaluating them. ${ }^{61}$

A mediator is more likely to reduce optimistic overconfidence by asking a lawyer to put himself in the place of a disagreeable adjudicator, rather than merely to identify weaknesses in his position or counterarguments. Researchers have found that subjects believe an outcome is more likely to occur if they explain why it might - a phenomenon labeled the "explanation bias."62 This is consistent with the finding that overconfidence results when

59 See Farnsworth, supra note 50, at 584 (questioning the value in reducing selfserving biases of asking lawyers to identify weaknesses in his case).

60 See, e.g., Babcock et al., supra note 57, at 918 (finding that listing weaknesses of their case reduced overconfidence in MBA student subjects participating in a litigation bargaining experiment).

61 This prediction is also consistent with the hypothesis that people who consider counter arguments after already reaching a judgment-as opposed to those who consider negative arguments before establishing an initial judgment - will be likely to downplay those arguments in an effort to maintain cognitive consistency. $C f$. Hoch, supra note 14, at 729 (noting that studies that test the effect of considering counter arguments usually have the decision maker do so before making a prediction, and that results might be quite different if decision makers make a prediction, identify counter arguments, and then reevaluate their prediction).

62 See Craig A. Anderson et al., Perseverance of Social Theories: The Role of Explanation in the Persistence of Discredited Information, 39 J. PERSONALITY \& SoC. PSYCHOL. 1037, 1047 (1980). 
differential attention is paid to facts that support, rather than undermine, an optimistic prediction, because providing an explanation for a possible desirable outcome focuses the decision maker's attention on facts that support that explanation. In the mediation context, these effects tend to merge, as lawyers explain to the mediator and the opposing side why they believe their client will prevail if the case goes to court. No matter how strong their case or how high their confidence level, however, almost all lawyers will concede that there is some possibility that their client will not prevail in adjudication. The mediator can take advantage of this by asking the lawyer to assume that his client actually does lose his case in court, and to explain the reasoning the judge (or jury) would most likely provide to support this contrary judgment. Generating a specific explanation for an undesirable judicial determination can increase its perceived plausibility, and thus often reduce, if not eliminate optimistic overconfidence. ${ }^{63}$

\section{Facilitate De-Biasing of the Opposition}

A second way mediators might approach the impediment of optimistic overconfidence is by attempting to facilitate a process by which the parties de-bias each other. The most straightforward way to attempt this intervention is for the mediator to convene the disputants and lawyers in a joint session and ask each side to present the arguments that they plan to make in court, show documents they intend to introduce, and provide summaries of expert testimony that they plan to use should mediation fail. Even if the lawyers have anticipated the general tenor of the arguments that their adversary will advance, actually hearing the adversary state his case can often persuade the listener that the speaker's case is stronger than the listener anticipated, thus reducing his level of confidence in success in court. ${ }^{64}$

My sense is that this intervention is often effective, although some of the same problems with asking lawyers to make the other party's arguments can

${ }^{63}$ Cf. Adam D. Galinsky \& Gordon B. Moskowitz, Counterfactuals as Behavioral Primes: Priming the Simulation Heuristic and Consideration of Alternatives, $36 \mathrm{~J}$. EXPERIMENTAL SOC. PSYCHOL. 384, 402-03 (2000) (finding that considering counterfactual outcomes can affect judgments about the likelihood of the assumed outcome); Edward R. Hirt \& Keith D. Markman, Multiple Explanation: A Consider-anAlternative Strategy for Debiasing Judgments, 69 J. Personality \& Soc. PSYCHOL. $1069,1083-1084$ (1995) (suggesting that generating an explanation for an alternative outcome can break a decision maker's single-minded focus on his focal hypothesis).

${ }^{64}$ See also Jean R. Sternlight, Lawyers' Representation of Clients in Mediation: Using Economics and Psychology to Structure Advocacy in a Nonadversarial Setting, 14 OHIO ST. J. ON DISP. RESOL. 269, 336-37 (1999). 
be apparent here as well. Specifically, while some lawyers take advantage of the opportunity to internalize and consider the force of the opponent's arguments, others forego this opportunity and focus their attention on refuting-or preparing to refute-the statements made.

\section{Directly Questioning Litigation Evaluations}

Finally, mediators can attempt to directly de-bias parties. This means unapologetically challenging the parties' evaluations-specifically, explaining the weaknesses in their positions or even providing predictions of how likely they are to prevail in court that diverge from their predictions, sometimes sharply. This approach is likely to have a greater effect on nonlawyer parties than on their attorneys, but, in my experience, this approach often shakes the confidence even of lawyers, and even when they believe that their case is extremely strong. It would be unusual for a lawyer to adopt a mediator's evaluation in toto. But when the mediator's evaluation is substantially more pessimistic than the lawyer's, my experience is that this usually tempers the lawyer's confidence and causes the lawyer to at least consider the possibility that her evaluation might be somewhat overconfident.

Many mediation theorists contend that mediators should not evaluate the legal merits of disputes; that evaluation is not the mediator's job, that it deprives the parties of autonomy, that it makes the mediator too central to the mediation process, and that it makes legal liability - that is, what a court would determine- too central a consideration in the mediation. Although there is merit to all of these criticisms of mediator case evaluation, I do not believe mediators can successfully and consistently overcome the overconfidence barrier without aggressive evaluation. Far from being an elective approach, direct evaluation is often necessary to overcoming the overconfidence bias and avoiding impasse when settlement is in the best interests of both parties.

\section{ATTRIBUTION BIASES}

\section{A. The Psychological Basis of Attribution Biases}

Attribution theory considers how people attribute causal meaning to behavior. ${ }^{65}$ Of primary concern in the mediation context is what happens

65 See Keith G. Allred, Anger and Retaliation in Conflict: The Role of Attribution, in The HANDBook of Conflict Resolution 236, 237 (Morton Deutsch \& Peter T. 
when another person takes an action that creates negative consequences for us, or that we otherwise experience negatively.

To what causal factor or factors do we attribute negative events? We can choose either to attribute an event to dispositional characteristics on the part of the actor who caused the event or situational characteristics. 66 Dispositional characteristics concern the character or personality traits of the actor who has created the negative situation for us. ${ }^{67}$ They are associated with individual control or agency; that is, we usually assume people can control dispositional characteristics. Situational characteristics, on the other hand, are external circumstances that are usually beyond the control of the actor; that is, when we view situational characteristics as critical to an event, we conclude that resulting consequences are beyond the actor's control. ${ }^{68}$ Put slightly differently, whether we perceive a negative event to result from primarily dispositional or primarily situational characteristics bears on whether we assign responsibility to the actor who caused that event. 69

Dispositional attributes of negative events, especially dispositional attributes perceived as controllable, tend to result in a particular emotion: anger. ${ }^{70}$ Imagine, for example, that you are stranded in an airport during a long flight delay. Whether you become angry at the airline probably will depend on whether you attribute the delay to bad weather (a situational factor) or poor planning on the part of the airline (a dispositional factor), although the attributional choice does not affect the tangible harm you suffer: the delay is the same either way. Bad weather is beyond the airline's control; poor planning is within its control. Often, both situational and dispositional

Coleman eds., 2000); Harold H. Kelly \& John L. Michela, Attribution Theory and Research, 31 ANN. REV. PSYCHOL. 457, 458 (1980).

66 See Daniel T. Gilbert, Attribution and Interpersonal Perception, in ADVANCED SOCIAL PSYCHOLOGY 99, 102 (Abraham Tesser ed., 1995).

67 Id.

68 Id.

${ }^{69}$ Cf. Keith G. Allred, Anger and Retaliation: Toward an Understanding of Impassioned Conflict in Organizations, in 7 RESEARCH ON NEGOTLATION IN ORGANIZATIONS 27, 30 (Robert J. Bies et al. eds., 1999) (discussing the importance of responsibility in attribution research). Responsibility attributions usually turn more on control than intentionality. See, e.g., Thomas R. Shultz \& Kevin Wright, Concepts of Negligence and Intention in the Assignment of Moral Responsibility, 17 CANADIAN J. BEHAV. SCI. 97, 104 (1985) (finding that subjects' judged an actor responsible if harm was due to an intentional or negligent act).

70 Allred, supra note 65, at 242; cf. Martin N. Davidson \& Leonard Greenhalgh, The Role of Emotion in Negotiation: The Impact of Anger and Race, in 7 RESEARCH ON NEgotiation IN ORGanizations 3, 11-14 (Robert J. Bies et al. eds., 1999) (discussing the causes of anger in disputes). 
factors are "but for" causes of negative events. One way to interpret your situation is that, but for a snowstorm in Chicago, your plane would have arrived on time and there would have been no delay. Another way to understand your delay is that the airline, in order to maximize its profit, did not build enough time into its schedule to take account of the fact that bad weather is a regular occurrence. In this situation, you might choose to attribute the negative event primarily to dispositional or situational characteristics.

Attribution affects anger because a particular harm often has a different meaning to the victim if its cause was within the harmdoer's control than if it was not. In the former case, the tangible harm might be accompanied by feelings of being disrespected, demeaned, or otherwise treated unfairly, while the victim is unlikely to experience these feelings if she perceived the harm to be beyond the harmdoer's control. ${ }^{71}$

The last link in the logic chain is that anger makes disputants less concerned with their opponent's interests ${ }^{72}$ and, further, creates the impulse to affirmatively retaliate. ${ }^{73}$ People feel the desire to retaliate against those with whom they are angry, but not against those with whom they are not angry, even when the other person's actions have resulted in a negative experience. ${ }^{74}$ As a consequence, whether a particular lawsuit settles can depend not only on the parties' views of the legal merits (i.e., the likely result of adjudication), but also on how angry the parties are with each other (or how angry one party is with the other). Specifically, the mechanism that I propose causes the correlation between level of anger and likelihood of impasse is what I what I call a malevolent utility function. ${ }^{75} \mathrm{~A}$ party with a malevolent utility function places a positive value on preventing the

71 See Davidson \& Greenhalgh, supra note 70, at 13 (describing how appraisals of events determine anger).

72 See Keith G. Allred et al., The Influence of Anger and Compassion on Negotiation Performance, 70 Organizational Behav. \& Hum. Decision Processes 175, 183 (1997) (finding that negotiators who felt more anger and less compassion for their opponent had less regard for the other's interests and were less likely to achieve joint gains in the negotiation).

${ }^{73}$ Allred, supra note 65, at 242-43; Allred, supra note 69, at 32-34. Scholars who study motivations to impose collective punishment on rulebreakers have found a similar link between attributions of responsibility and a desire to impose punishment. See, e.g., Kevin M. Carlsmith et al., Why Do We Punish? Deterrence and Just Deserts as Motives for Punishment, 83 J. PERSONALITY \& SOC. PSYCHOL. 284, 287 (2002) (synthesizing studies).

74 See Allred, supra note 69, at 29-35.

75 See Jack Hirshleifer \& Evan Osborne, Truth, Effort, and the Legal Battle, in THE DARK SIDE OF THE FORCE: ECONOMIC FOUNDATIONS OF CONFLICT THEORY 131, 133 (Jack Hirshleifer ed., 2001). 
opposing party from obtaining what she wants from the lawsuit. ${ }^{76}$ The same settlement agreement that would be acceptable to you if you were not angry at the opposing party might be unacceptable if you have a malevolent utility function and believe that agreement to the proposal would leave your adversary content-if not overjoyed - with the outcome. ${ }^{77}$

To summarize: dispositional attributions lead to anger; anger helps to create malevolent utility functions; and malevolent utility functions reduce the likelihood of parties reaching agreement in mediation because the parties want not only to vindicate their legal entitlements but also to cause pain to their adversaries. Thus, dispositional attributions reduce the likelihood of mediation settlement. But is this cause for concern? Recall that my premise about what constitutes mediation success allows for the fact that people may have subjective preferences. According to this premise, there is nothing untoward about parties having malevolent utility functions: a preference for denying an adversary pleasure is no more objectionable than a taste for ice cream. And if two parties have utility functions such that there is no agreement that both would prefer to adjudication, impasse does not demonstrate a failure of mediation.

The problem, however, is that psychological research shows that people tend to attribute the behavior of other people to disposition, rather than situation, to a greater extent than is warranted. ${ }^{78}$ It appears that a strong belief in the power of disposition provides people with a comforting sense of their agency in the world and also that the subtleties of situational constraints that affect the actions of others are often difficult to identify and fully appreciate. ${ }^{79}$ Inferring a correspondence between the results of a person's

76 Cf. Allred, supra note 65 , at 244 (reviewing studies in which "angry negotiators had less positive regard for each other's interests in the negotiation"); Leonard Greenhalgh \& Deborah I. Chapman, Relationships Between Disputants: An Analysis of Their Characteristics and Impact, in WORKPLACE DISPUTE RESOLUTION 203, 206 (Sandra E. Gleason ed., 1997) (observing that in maximally adversarial relationships "[t]he feuding parties' motivation is ... to impose costs on the other party).

${ }^{77}$ Cf. Sternlight, supra note 64, at 306 (suggesting that a litigant who seeks vengeance may prefer trial with a lower expected value to settlement if she "feels that a proffered settlement would not sufficiently harm her opponent').

${ }^{78}$ See, e.g., Pronin supra note 55, at 640; Lee Ross \& Donna Shestowsky, Contemporary Psychology's Challenges to Legal Theory and Practice, 97 Nw. U. L. REV. 1081, 1092-93 (2003); Lee Ross, The Intuitive Psychologist and His Shortcomings: Distortions in the Attribution Process, in 10 ADVANCES IN EXPERIMENTAL SOCIAL PSYCHOLOGY 173, 184 (Leonard Berkowitz ed., 1977).

${ }^{79}$ See Gilbert, supra note 67, at 107-115 (describing causes of the correspondence bias); see also Didier Truchot et al., Do Attributions Change Over Time When the Actor's 
actions and her disposition may in fact be a generally useful heuristic that economizes on cognitive effort, even if it sometimes leads to faulty conclusions. ${ }^{80}$ Whatever the precise cause, the finding that people attribute too much of behavior to disposition and too little to situation, often labeled the "correspondence bias," 81 is such a robust and central result of social psychology research that it has also been called the "fundamental attribution error" (FAE) ${ }^{82}$ A related finding that further complicates matterssometimes called the "actor-observer" bias-is that, when we evaluate our own behavior that causes harm, we are likely to emphasize the situational constraints under which we operate as the causal factor and minimize the role of our own disposition. ${ }^{83}$

These attribution biases mean that when acts of others harm us, we are more likely to conclude that "they" are bad people who have acted with malice or indifference. This analysis, in turn, leaves us angrier than we would be if our assumptions were more accurate. ${ }^{84}$ In contrast, when we are the harmdoer we are more likely to believe, on average, that our actions are responses to unalterable situational constraints; that is, the harm we cause is due to the situation rather than to our dispositional characteristics. ${ }^{85}$ When these biases create divergent construals, emotional responses can build upon one another. Because the perpetrator perceives that the harm he caused was due to situational characteristics, the perpetrator is likely to view the victim's angry reaction as unwarranted and evidence of the victim's bad disposition, which, in turn, can make the perpetrator angry and desirous of retaliation.

This dynamic can be reinforced and deepened by a related bias known as "naîve realism." 86 We believe that our understanding of the world is authentic; that is, we assume that we see the world and the facts of the world as they truly are. ${ }^{87}$ It follows from this belief that if others do not agree with our view of the world or our view of facts, then they must be misinformed,

Behavior is Hedonically Relevant to the Perceiver?, 143 J. Soc. PsYCHOL. 202, 203 (2003) (noting that personal characteristics are often more salient than situational ones).

${ }^{80}$ See Paul W. Andrews, The Psychology of Social Chess and the Evolution of Attribution Mechanisms: Explaining the Fundamental Attribution Error, 22 EVOLUTION \& HUM. BEHAV. 11, 17 (2001).

${ }^{81}$ See Gilbert, supra note 66, at 105.

82 See Ross, supra note 78, at 183. See also Allred, supra note 65, at 240.

83 See Allred, supra note 69 , at 36 .

${ }^{84}$ See Allred, supra note 72, at 185.

85 See Allred, supra note 69, at 37.

86 See generally Lee Ross \& Andrew Ward, Psychological Barriers to Dispute Resolution, in 27 ADVANCES IN EXPERIMENTAL SOCIAL PSYCHOLOGY 255, 278-84 (Mark P. Zanna ed., 1995).

${ }^{87} \mathrm{Id}$. at 279. 
biased, insensitive, or self-interested. ${ }^{88}$ Once we explain the situational constraints that determined our actions, others can no longer claim to be misinformed. At that point, their claim to perceive the world differently than we do constitutes evidence of their bad character.

\section{B. Attribution Bias as an Impediment to Mediation Success}

Attribution bias can place mediation success at risk by increasing the parties' level of anger beyond what is objectively justified by the facts. When this happens, parties can adopt malevolent utility functions, making the need for compromise necessary to reach settlement appear less desirable and the possibility of complete victory in adjudication relatively more attractive. The ultimate consequence is the presence of a smaller bargaining zone than might exist in the absence of attribution bias- - or even the complete absence of a bargaining zone-which increases the risk of impasse and reduces the likelihood of settlement.

Consider the following example of a dispute I mediated. A plaintiff, who was injured by an act of the defendant's employee, brought a tort action against the defendant alleging vicarious liability based on the theory of respondeat superior. The damages were relatively modest. Given the transaction costs that would be required to try the case, I predicted that there should be a substantial bargaining zone, and that the case should settle in mediation.

Prior to the mediation I asked both lawyers privately if there were any issues about which they felt I ought to be aware. Both lawyers criticized the character of the opposing party. The plaintiff's lawyer told me that the defendant was utterly lacking in integrity. When the lawyer's client, the plaintiff, attempted to contact the defendant after suffering an injury, the defendant never responded. Instead, she completely ignored the plaintiff and his problem. In addition, the defendant's advertisements for her business, which originally attracted the plaintiff, were riddled with lies and misrepresentations. In short, the defendant was an all-around bad person. The defendant's lawyer, in turn, warned me that the plaintiff was a hysterical lunatic. Rather than contacting his client and making a good faith effort to resolve the matter, he claimed, the plaintiff took a small problem and blew it completely out of proportion.

Steeled for the possibility of a nasty mediation session, I was pleasantly surprised when I met the parties. Both seemed quite reasonable when explaining to me their views of the dispute and their positions. After listening

${ }^{88} \mathrm{Id}$; see also Ross \& Shestowsky, supra note 78, at 1090-91. 
to both, I believed that the primary problem was an unfortunate miscommunication that led to a series of misattributions and created unnecessary anger on both sides. As a consequence of this anger, however, the defendant clearly didn't want to leave the mediation with the plaintiff satisfied, so the defendant offered a very small amount of money to settle the case. The plaintiff, for his part, was not about to let the defendant off the hook easily. Even though his damages were relatively modest, he demanded a very large settlement. The dispute was no longer entirely about whether the defendant was legally liable for the plaintiff's' injuries. It had become more about who would triumph in a battle of wills. ${ }^{89}$

Of course, the parties' demands could be explained in part as strategic blustering, rather than an honest disclosure of bottom-line positions. But even taking this into account, I was quite confident that there was no bargaining zone-no potential agreement that both parties would prefer to continued litigation. This state of affairs, I believe, was created by uncharitable attributions by both parties concerning the other's character, and the firm belief on each side that their perception of the events that led them to litigation was unbiased. Had the parties attributed the facts that created the dispute to situational rather than dispositional characteristics, the defendant might have been willing to pay more to settle the dispute, and the plaintiff might have demanded far less. Empathy might have partially substituted for antagonism, and the parties might have been better able to view the dispute as a joint problem to solve rather than a battle in which to prevail.

\section{Potential Interventions}

When faced with attribution biases that threaten impasse in a dispute that otherwise might settle, how might the mediator respond?

Again, one option is to explain the concept of attribution bias to the parties and explain the possible consequences of attribution biases. At least one study has found that education can reduce such biases in experimental subjects, ${ }^{90}$ and scholars have hypothesized that increased awareness of these biases can reduce their impact in particular cases. ${ }^{91}$

${ }^{89}$ Cf. Greenhalgh \& Chapman, supra note 76 , at 208 (observing that when there is a lack of civility, dispute resolution becomes more difficult because "concessions carry with them a loss of social face"). Each disputant sees making concessions "as an act of submission in their battle of wills." Id.

90 Mei-whei Chen et al., Deconstructing Dispositional Bias in Clinical Inference: Two Interventions, 76 J. CoUNSELING \& DEV. 74, 78-79 (1997).

91 See, e.g., Ross \& Ward, supra note 86, at 297. 
I have had little success with this approach. In my experience most parties and their attorneys respond to a description of attribution biases by accepting that they exist but remaining convinced that their particular adversary is a malicious, evil, obnoxious, negligent jerk. When parties respond in this way, the mediator has no good rejoinder, because he cannot say with certainty that the disputant's perception of the particular case is biased. After all, some people are malicious, evil, indifferent, negligent jerks, and the litigant's adversary might well be one of them. Not only does the mediator have no proof to the contrary, the parties have considerably more evidence concerning the personality of their adversaries than the mediator does. The evidence of the FAE and naïve realism can cause mediators to believe that, on average, disputants over-attribute events to the bad character of their adversaries, but this provides no firm basis for contradicting a party's claim about his adversary in any particular case. The fact that such an attribution is biased on average does not mean, of course, that disposition is never primarily responsible for observed behavior.

A second possible intervention is for the mediator to encourage the parties to explain to each other the reasons for their actions and to avoid focusing on blame or on legal liability. ${ }^{92}$ By keeping the parties away from the issue of legal liability, at least initially, the mediator might help the parties create more understanding of the situational constraints faced by each other, thus reducing anger and increasing empathy.

This tactic can be successful. Research in social psychology has shown that providing an explanation of mitigating circumstances for one's behavior can improve perceptions in the eyes of others. ${ }^{93}$ But it is a quite risky approach. The problem is that parties who already think badly of their adversary often respond to the explanations and description of intentions provided by that adversary with additional uncharitable attributions. This is hardly surprising in light of another finding of social psychology: that our expectations of how others will act influence our understanding of their behavior. ${ }^{94}$ Thus, after hearing his adversary's woeful tale of situational constraints, the listening party might now believe not only that his adversary

$92 C f$. Allred, supra note 65 , at 250-251 (recommending that people whose actions have a negative effect on others explain their behavior, as others are often unaware of mitigating factors).

93 See, e.g., Robert J. Bies, The Predicament of Injustice: The Management of Moral Outrage, in 9 RESEARCH IN ORGANIZATIONAL BEHAVIOR. 289, 298-300 (1987) (describing experimental results).

94 See, e.g., D.L. Rosenhan, On Being Sane in Insane Places, 179 SCIENCE 250, 252 (1973) (seven of eight experimental confederates who checked themselves into mental hospitals were diagnosed as schizophrenic by admitting psychiatrists). 
is a malicious, evil, indifferent jerk, but that he is a liar as well. ${ }^{95}$ Often there will be something to this attribution. Studies reinforce the intuitive suspicion that harmdoers tend to exaggerate the extent of the situational constraints they face even relative to what they actually believe, ${ }^{96}$ although they might also internalize such exaggerations. ${ }^{97}$

The bottom line is that a harmdoer's explanation that emphasizes situational constraints can increase the victim's anger, which in turn will often reduce the victim's willingness to make sacrifices to settle the case and thus increase the likelihood of impasse. This reaction can also have a boomerang effect. The harmdoer, as naïve realist, might initially attribute the victim's anger to an information deficit: that is, he might assume that the victim is not aware of the situational constraints faced by the harmdoer. After the victim is "enlightened" however, his failure to adjust his attitude can be perceived as evidence of his bad faith or maliciousness, which can fuel the harmdoer's malevolent feelings toward the victim. ${ }^{98}$

Here, an apology offered by the harmdoer can be helpful in breaking the cycle of increasing anger. An explanation of behavior is more likely to create empathy and less likely to reinforce negative attributions if it is accompanied with an apology for the act that caused harm. An apology can signify both an acceptance of responsibility by the harmdoer and a claim that the act that caused harm is not an authentic reflection of the harmdoer's disposition. ${ }^{99}$

Neither acceptance of responsibility nor a claim that the harmdoer acted out of character is likely to cause the victim to forfeit his legal claim, but it is likely to reduce feelings of malevolence that can cause impasse. Most victims will continue to demand compensation for tangible harms suffered, but there is no need to additionally punish someone who has accepted responsibility. ${ }^{100}$ This is an important subtlety that litigants and their lawyers

95 See Fiona Lee \& Robert J. Robinson, An Attributional Analysis of Social Accounts: Implications of Playing the Blame Game, 30 J. APPLIED SOC. PSYCHOL. 1853 (2000) (finding in a study of social accounts that the more the account emphasized external attributions the less truthful it was perceived to be and the more negative attributions of the character of the account giver).

96 See Allred, supra note 69, at 41.

97 See Bies, supra note 93, at 313.

98 Cf. Ross \& Ward, supra note 86 , at 280-81 (claiming that bias is often inferred when an other fails to accept our world view after being presented with the relevant facts).

${ }^{99}$ See Bies, supra note 93, at 302-03.

$100 \mathrm{Cf}$. Allred, supra note 69, at 43 ("Presumably, much of the purpose in retaliating against others who are responsible for harmful behavior is to persuade them to accept responsibility."); Bies, supra note 93, at 304 (concluding from studies that harmdoers who offer "penitential" accounts of their actions receive lesser sanctions); Seiji Takaku, 
often fail to recognize, thinking that there is no point in offering an apology if they believe that - as is usually the case-the victim is unlikely to accept the apology as full compensation and dismiss his claim. In experimental situations, apologies have been shown to reduce feelings of anger, ${ }^{101}$ to reduce punishment meted out to wrongdoers by victims, ${ }^{102}$ and to increase the likelihood that the recipient would be willing to accept a given litigation settlement offer, ${ }^{103}$ especially when it is clear that the apology signifies an acceptance of responsibility rather than merely an expression of sympathy. ${ }^{104}$ This effect can be bolstered if the mediator can convince the victim to imagine himself in the position of the harmdoer and thereby develop empathy. 105

A third intervention that I have found can help dampen negative attributions is for the mediator to provide the parties in private caucus a plausible explanation of their adversary's actions that emphasizes situational constraints. For example, the mediator might concede that it is possible that the adversary is a malicious, obnoxious jerk but suggest that the mediator finds another hypothesis more plausible - and then provide an account of the events that is consistent with the observed outcome but attributes a more situationally-dependent motivation for the adversary's actions. The goal here

The Effects of Apology and Perspective Taking on Interpersonal Forgiveness: A Dissonance-Attribution Model of Interpersonal Forgiveness, 141 J. SOC. PSYCHOL. 494, 505-06 (2001) (concluding from studies that an apology reduces the likelihood that victims will punish harmdoers).

101 See, e.g., Mark Bennett \& Deborah Earwaker, Victims' Response to Apologies: The Effects of Offender Responsibility and Offense Severity, 134 J. SOC. PSYCHOL. 457 (1994).

102 See Ken-ichi Ohbuchi et al., Apology as Aggression Control: Its Role in Mediating Appraisal of and Response to Harm, 56 J. PERSONALITY \& SOC. PSYCHOL. $219,220-222$ (1989) (finding subjects less likely to give poor ratings to, and thus damage the grades of, the experimenters' confederates who made "mistakes" in administering a test if they apologized).

103 Russell Korobkin \& Chris Guthrie, Psychological Barriers to Litigation Settlement: An Experimental Approach, 93 MICH. L. REV. 107, 147-50 (1994).

104 See Jennifer K. Robbennolt, Apologies and Legal Settlement: An Empirical Examination, 102 MICH. L. REV. 460, 486 (2003) (finding that "full" apologies increase the likelihood of settlement but "partial" apologies that are mere expressions of sympathy can actually decrease the likelihood of settlement).

105 See Takaku, supra note 100, at 505-06. But see Incheol Choi \& Richard E. Nisbett, Situational Salience and Cultural Differences in the Correspondence Bias and Actor-Observer Bias, 24 PERSONALITY \& SOC. PSYCHOL. BULL. 949, 958 (1998) (finding that Korean, but not American, subjects exhibited a reduced correspondence bias when they were placed in the same situation as the person whose behavior they were to judge). 
is not to convince the party that his adversary is an innocent victim of situational constraints beyond all means of control. Rather, by making salient an alternative explanation the mediator can undermine the party's certainty that his level of anger and accompanying malevolent feelings are fully justified.

\section{FRAMING EFFECTS}

\section{A. The Psychology of the Framing of Risky Choices}

Rationalist decision theory assumes that people evaluate and choose between options exclusively on the basis of each option's tangible features, without regard to how the options are described or classified. Psychologists have documented, however, that the framing of choices often matters. Perhaps the strongest, most consistent evidence concerning the surprising effect of frames on decision making has been gathered in the context of choices between one risky option and one certain option. ${ }^{106}$ In this situation, experiments have repeatedly found that subjects express a stronger preference for the certain option when the choice is framed as one between "gains" than when the same choice is framed as one between "losses."107 Another way to put this point is that decision makers often evaluate options in relation to some reference point and are likely to have a greater taste for risk when both choices are bad in relation to the referent than when the choices are good in relation to the referent. ${ }^{108}$

Early examples of the effect of gain and loss frames on a choice between a risky and a riskless alternative devised by Amos Tversky and Daniel Kahneman remain paradigmatic. In one experiment, a majority of subjects preferred a public health intervention to control a disease affecting 600 people that would save 200 for certain to one with a $1 / 3$ chance of saving 600

106 See Anton Kühberger, The Influence of Framing on Risky Decisions: A Metaanalysis, 75 ORganizational Behav. \& HuM. Decision Processes. 23, 36 (1998) (drawing conclusions from a meta-analysis of experiments which choice contexts result in the largest and most consistent framing effects). For a useful typology of different framing effects, of which "risky choice framing" is just one, see generally Irwin P. Levin et al., All Frames are Not Created Equal: A Typology and Critical Analysis of Framing Effects, 76 Organizational BeHAV. \& HuM. Decision Processes 149 (1998).

107 See Kühberger, supra note 106, at 40 (finding the most robust effects of frames on choice for experiments with a "gain/loss" manipulation).

108 This is one of the fundamental postulates of prospect theory. See Daniel Kahneman \& Amos Tversky, Prospect Theory: An Analysis of Decision Under Risk, 47 ECONOMETRICA 263, 263 (1979); Amos Tversky \& Daniel Kahneman, Rational Choice and the Framing of Decisions, 59 J. BuS. S251, S258-60 (1986). 
and a $2 / 3$ chance of saving none, but a majority also preferred an intervention with a $2 / 3$ chance of losing all 600 lives and a $1 / 3$ chance of losing none to one that would result in the certain loss of 400 lives. 109 In another experiment, a large majority of subjects preferred a certain $\$ 240$ to a $25 \%$ chance of receiving $\$ 1,000$, but a large majority also preferred a $75 \%$ chance of losing $\$ 1,000$ to a certain loss of $\$ 750 .{ }^{110}$ In both versions of the disease scenario, the riskless choice would result in 200 saved and 400 dead, and the risky choice would result in a $1 / 3$ chance that all 600 would live and a $2 / 3$ chance that all 600 would die, yet the framing of the choice in terms of saving lives (gains) provoked risk-averse choices while the framing of the choice in terms of losing lives (losses) provoked risk-preferring choices. ${ }^{111}$ In the monetary gamble, faced with opportunities to gain (or possibly gain) money, most subjects preferred the riskless option even though it had a slightly lower expected value than the risky option. Faced with losing (or possibly losing) money, however, most subjects preferred a gamble that had the same expected value as the riskless option.

Chris Guthrie and I demonstrated experimentally one way that the framing of risky and riskless choice could affect settlement behavior in the litigation context. ${ }^{112}$ In one experiment, we asked subjects to play the role of the plaintiff in a lawsuit resulting from an automobile accident caused by the other driver in which the subject had been injured slightly and suffered the complete loss of his or her car. ${ }^{113}$ Subjects were faced with a choice between accepting a settlement offer of $\$ 21,000$ or taking their case to trial, which was described as having a roughly $50 \%$ chance of resulting in an award of $\$ 10,000$ (which the defendant's insurance company claimed with its policy limits) and a roughly $50 \%$ chance of resulting in an award of $\$ 28,000$ (which represented the plaintiff's full damages). ${ }^{114}$ Researchers told half of the subjects that $\$ 14,000$ of the damages suffered were medical costs that had been reimbursed by their health insurance company and $\$ 14,000$ represented the value of their car. ${ }^{115}$ The other half was told that $\$ 4,000$ of the damages

109 See Tversky \& Kahneman, supra note 108, at S260.

110 Id. at $\mathrm{S} 255$.

111 See also Max H. Bazerman \& Margaret A. Neale, Heuristics in Negotiation: Limitations to Effective Dispute Resolution, in NEGotIATING IN ORGANIZATIONS 51, 54 55 (Max H. Bazerman \& Roy J. Lewicki eds., 1983) (reporting results from a similarly designed experiment).

112 Korobkin \& Guthrie, supra note 103, at 130-38.

113 Id. at 131.

114 Id. at $131-32$.

$115 \mathrm{Id}$. at 132. 
suffered were medical costs that had been reimbursed, while $\$ 24,000$ represented the value of the lost car. ${ }^{116}$ Although both groups of subjects faced the same choice between a certain $\$ 21,000$ and gamble with an expected value of $\$ 19,000$, we hypothesized that members of the first group would undoubtedly see the certain choice as a gain and the risky choice as a chance of a larger gain, while members of the second group might perceive the certain choice as a loss (because it would not provide enough money to replace their car) and the risky option as the only possibility of avoiding a loss. Subjects in the first group overwhelmingly favored accepting the certain settlement, whereas subjects in the second group were more likely to opt for the risky trial. ${ }^{117}$

\section{B. The Framing of Risky Choices as an Impediment to Mediation Success}

For the effects of risky choice framing to be relevant, a particular decision context requires two elements. First, the decisionmaker must face a choice between a risky and a riskless (or near riskless) option. ${ }^{18}$ Second, there must be competing reference points that decision makers might adopt when evaluating options. The first requirement is obviously satisfied in the litigation bargaining context, of which mediation is one particular case: settlement provides a certain outcome-or, at least relatively certainwhereas the alternative, adjudication, is always risky, nearly always offering a chance of a better outcome than settlement and a chance of a worse outcome. What reference points disputants might plausibly employ when analyzing the choice of settlement versus adjudication is a more complicated issue. One reference point that is always plausible-and that I will argue below is normatively appropriate-is the expected value of adjudication, taking into account the associated transaction costs of continuing to prosecute the case in court. As the Korobkin and Guthrie experiment discussed above exemplifies, the range of plausible competing reference points can be quite context-specific. I believe, however, that two are most common.

First, disputants might use their status quo financial position at the time of the mediation as a reference point. Viewed from this reference point, any settlement that requires a payment to the plaintiff will be framed as a loss to

116 Id.

$117 \mathrm{Id}$. at 133.

118 Results of framing experiments have been far less robust when decision makers face a choice between "more risky" and "less risky" choices. See Kühberger, supra note 106 , at 43. 
defendants and as a gain to plaintiffs. This does not mean, of course, that plaintiffs who adopt the status quo as a reference point will be inclined to accept any non-zero settlement and that defendants will be inclined to reject any non-zero settlement. It does suggest, however, that plaintiffs are likely to be more risk averse than defendants, and that defendants even might be risk preferring in an absolute sense-that is, defendants might choose to decline a particular settlement even when the expected value of going to adjudication is substantially worse in order to preserve the chance of avoiding the certain "loss" that a settlement would impose. In one study that supports this hypothesis, the experimenter assigned subjects the role of plaintiff or defendant in a lawsuit, gave them information on the plaintiff's likelihood of prevailing in adjudication and the likely damage award, and asked them whether they would prefer a settlement precisely equal to the expected value of adjudication. ${ }^{119}$ A large majority of plaintiff subjects expressed a preference for accepting the settlement offer, whereas most defendants expressed a preference to decline the settlement offer and take their chances with adjudication. ${ }^{120}$

Second, disputants in mediation might evaluate the settlement vs. adjudication choice from the perspective of their aspiration level, defined as a goal or a target settlement value that they wish to achieve and that is not directly derived from the expected value of taking the case to adjudication. ${ }^{121}$ If either party comes to mediation with an aggressive aspiration level and implicitly references it when evaluating settlement possibilities, the aspiration will frame the choice as one between a certain loss and a chance of a larger loss coupled with the chance of avoiding the loss. ${ }^{122}$ The predicted consequence of this framing is that the disputant will demonstrate a higher tolerance for risk than he would if he used the expected value of adjudication as his framing device, effectively shrinking the bargaining zone and making settlement less likely. If both parties have aggressive aspirations and use them to frame their decision making in mediation, the increased likelihood of impasse as a result can double.

119 Jeffrey J. Rachlinski, Gains, Losses, and the Psychology of Litigation, 70 S. CAL. L. REV. 113, 135-40 (1996).

$120 \mathrm{Id}$.

121 For a more complete definition, see Russell Korobkin, Aspirations and Settlement, 88 CORNELL L. REV. 1, 3 (2002). as frames).

${ }^{122}$ See id. at 33-36 (providing a theory of how aspirations can be used by litigants 
I have conducted a series of experiments that suggests many disputants might be prone to rely on aspiration levels as reference points. ${ }^{123}$ Lawstudent subjects, asked to assume the role of either the plaintiff's or the defendant's lawyer in a variety of lawsuit scenarios, were told the minimum amount that they had already decided they would be willing to accept to settle the case (i.e., a reservation price). ${ }^{124}$ In any given scenario, half of the subjects were given an aggressive aspiration level and half were given a more modest aspiration level. ${ }^{125}$ All subjects were then asked to consider a settlement offer that was lower than the aggressive aspiration level but equal to or higher than the moderate aspiration level. ${ }^{126}$ Subjects given an aggressive aspiration level were significantly more likely to say that they would engage in negotiating behavior that would prolong settlement negotiations ${ }^{127}$ and behavior that would risk causing the negotiations to fail entirely. ${ }^{128}$ Because the only systematic difference between the subject groups was their assigned aspiration level, I interpret the difference in average responses as evidence that (at least some) subjects focused attention on their aspiration level and implicitly framed settlement offers as gains or losses accordingly. Subjects with aggressive aspirations could view their choices through a loss frame in a way that subjects with moderate aspirations could not, and the former subjects therefore were more willing to take risks that could cause delay or imperil settlement.

Details of the following mediation that I conducted illustrate, I believe, the effect that implicitly referencing the status quo at the time of mediation and/or aggressive aspirations can have on mediation outcomes. The plaintiff, who had provided services for the defendant's company, filed a breach of contract lawsuit against the defendant for failing to pay the plaintiff's bills totaling $\$ 200,000$. At the mediation session, the defendant claimed that the plaintiff had not provided all of the services for which he, the defendant, had been billed. At best, then, the defendant had only a partial defense to the lawsuit; in court, the defendant might succeed in having the amount of the bill reduced, but there was virtually no possibility that he could prevail entirely.

In light of the transaction costs of adjudicating the matter, the time that would lapse before he received any money, and the possibility that he would have trouble collecting a judgment, the plaintiff offered to settle the matter

$123 \mathrm{Id}$. at $36-53$.
$124 \mathrm{Id}$. at $36-37$.
$125 \mathrm{Id}$.
$126 \mathrm{Id}$.
$127 \mathrm{Id}$. at $44-48$.
$128 \mathrm{Id}$. at $50-52$. 
for a payment of $\$ 160,000$, or a twenty percent discount off of the amount billed. Perhaps in the course of negotiations the plaintiff would have made some further concessions, but this seemed to me to be a reasonable offercertainly a fair place to start. The defendant declined the offer. Initially, he refused to make any counteroffer at all; pressure from his lawyer and myself caused him to agree, reluctantly to offer $\$ 25,000$ to settle the case. During the remainder of the mediation session, he would make no further concessions. When I pressed the defendant as to why he was unwilling to increase his offer when his best-case scenario in adjudication was to receive a modest discount off of the $\$ 200,000$ bill, he explained that he could not afford to pay more than $\$ 25,000$. My suggestion that the plaintiff would likely be willing to accept installment payments failed to convince him to raise his offer. Since $\$ 25,000$ was far below the plaintiff's reservation price-probably more than $\$ 100,000$ below-the mediation ended without agreement.

My analysis was that the defendant's perception of all realistic settlement possibilities - say, between $\$ 100,000$ and $\$ 160,000$ - as losses caused him to engage in more risk-preferring behavior than he might have if he had viewed a settlement as a gain relative to the expected value of adjudication. If this is correct, the frame impeded settlement. It is a more difficult question of whether the frame was an impediment to mediation success, as I have defined that term.

It is important to note that when a disputant chooses the risky course of adjudication over the certain option of settlement this does not necessarily constitute a failure of mediation, even if the settlement has a higher expected value. Disputants might have articulable reasons to choose a risky course of action in an attempt to avoid accepting a certain loss, even if the risk involves long odds. Risk aversion or even risk neutrality are not always normative. For example, assume that the defendant in this mediation would have been forced to declare bankruptcy had he agreed to pay the plaintiff any amount more than $\$ 25,000$. In this situation, the defendant might logically choose to refuse to pay more than $\$ 25,000$, even though the expected value of litigation approached $\$ 200,000$. Under such conditions, there might be no practical difference to the defendant between settling for $\$ 30,000$ and losing a verdict of $\$ 180,000$ - both would result in bankruptcy-whereas litigation would provide a chance, however small, of saving his business.

In this particular case, however, there was no such explanation for the defendant's extreme, risk-preferring behavior-at least not one that I could discern. My evaluation was that his refusal to increase his settlement offer was attributable not to a rational decision to favor risk but to a focus on an arbitrary and unrealistic aspiration level or on a temporary status quo (one in 
which he had made use of the plaintiff's labor but had paid nothing) that he had no reasonable expectation would persist. This created an emotional preference for risk that he probably would not otherwise have felt. Had the defendant selected $\$ 175,000$ rather than $\$ 25,000$ as his aspiration level, my guess is that he would have been quite pleased to accept the plaintiff's offer. So, in this case, I would argue that the framing effect did serve as an impediment to mediation success: a bargaining zone would have existed and settlement would have been possible, if not for the selection of an essentially arbitrary reference point.

\section{Possible Interventions}

In order to avoid an impasse that results from the framing of a risky choice, the mediator should attempt to change the reference point from which the disputant evaluates the possibility of settlement, such that settlement appears to be a gain rather than a loss. Usually, this will mean suggesting that an alternative reference point is more appropriate than the reference point that the disputant has implicitly selected. The most appropriate reference point generally monetizes the expected value or cost of litigating the outstanding legal claim to judgment. The party's lawyer will often assist the mediator in this intervention. Both my prior experimental research ${ }^{129}$ and my mediation experience suggest that lawyers are more likely than their clients to evaluate the settlement decision using the expected value or cost of litigation as a reference point rather than unrealistic aspiration levels or bestcase scenarios. ${ }^{130}$

In the above example, the defendant's unreasonable aspiration resulted in a very aggressive reference point, compared to which any reasonable settlement possibility appeared quite undesirable. This reference point was unreasonable because its validity implicitly rested on the assumption that the defendant was entitled to all or at least most of the money in his physical possession at the time of the mediation. In reality, his nominal financial position was quite misleading, because of the unliquidated debt owed to the plaintiff. His current financial "portfolio" included not only a certain amount of liquid assets, on which he appeared to focus his attention, but also a

129 See Korobkin \& Guthrie, supra note 44, at 95-101.

130 See also Guthrie et al., supra note 27, at 778 (finding magistrate judges are less likely to be susceptible to framing effects than other cognitive biases). $C f$. Sternlight, supra note 64, at 312 (stating that an important role of lawyers in mediation "is to 'reframe' options to their clients to encourage settlements"); Ian Weinstein, Don't Believe Everything You Think: Cognitive Bias in Legal Decision Making, 9 CLINICAL L. REV. 783,820 (2003) (claiming that "[l]awyerly habits of careful, objective reasoning help us spot and respond to framing biases"). 
lawsuit that had a very high expected cost. Taking into account the lawsuit, his actual financial position consisted of his current financial holdings minus an expected court judgment of approximately $\$ 180,000$, minus expected transaction costs of litigating the matter of at least $\$ 20,000-\$ 30,000$. If I had been able to convince the defendant to accept this reference point, a settlement agreement according to which he paid the plaintiff $\$ 50,000$, $\$ 100,000, \$ 150,000$, or even $\$ 160,000$, would have appeared to be a gain.

An alternative approach is for the mediator to attempt to focus the parties' attention on the differential transaction costs of settlement and continued litigation. Because the marginal transaction cost of settling during the mediation (after the parties have already invested in preparation, attendance, hiring the mediator, etc.) is close to zero and the costs associated with taking the matter to court are usually quite significant, focusing on transaction costs emphasizes a positive aspect of settlement and a negative aspect of adjudication. (As a side note, research on "goal framing"-a concept similar to but conceptually distinct from "risky choice framing"suggests that this effort is more likely to yield the desired results if the mediator warns the parties that a failure to settle will cause them to suffer high transaction costs than if the mediator encourages the parties to settle in order to save on transaction costs. ${ }^{131}$ Even though the mediator makes the exact same substantive point either way, research suggests that the identical information can have a greater impact on decision making when presented in "loss" rather than "gain" terms. ${ }^{132}$ )

This approach has special challenges in cases involving plaintiffs with lawyers who are being paid on a contingent fee basis, because these plaintiffs often perceive the marginal transaction costs of adjudication to be zeroafter all, any compensation received by the lawyer comes out of proceeds. The perception of the costless trial is usually false, however. Often the plaintiff will have to pay litigation costs (other than attorneys' fees) out of pocket; which can be quite expensive, especially if expert witnesses are necessary. In jurisdictions with offer-of-settlement rules, a plaintiff who fails to recover through adjudication more than the defendant formally offers can be responsible for some or all of the litigation costs the defendant incurred after the offer-of-settlement is made. ${ }^{133}$ Pointing out the significance of these costs can often help to convince a plaintiff, who might otherwise perceive litigation as only a range of "upside" results that settlement would limit, that

131 See Levin et al., supra note 106, at 167-178.

$132 \mathrm{Id}$. at $176-78$.

133 See, e.g., FED. R. CIV. P. 68. 
litigation is actually a costly endeavor, compared to which settlement can look like a certain gain.

\section{REACTIVE DEVALUATION}

\section{A. The Psychology of Reactance and Reactive Devaluation}

Reactance theory posits that limitations placed on an individual's freedom triggers an affective reaction. ${ }^{134}$ Specifically, when an option or course of action becomes unavailable to an individual, he is likely to view it as more attractive than it previously appeared to be. ${ }^{135}$ In lay terms, this is a version of the "grass is always greener on the other side of the fence" phenomenon. Psychologists have developed a branch of reactance theory of particular relevance to bargaining interactions. This version of the theory, "reactive devaluation," makes a prediction that is, in some ways, the inverse of classic reactance theory: a concession or compromise that is offered appears less desirable than it appeared before it was offered. ${ }^{136}$ That is, grass growing on our side of the fence looks less green than it did when it was growing on the other side of the fence.

There are at least four different motivational explanations for why a negotiator might devalue an offer or concession in negotiation. Understanding that the observed behavior does not necessarily have a single source is a necessary first step for designing mediation interventions.

First, a negotiator might devalue an offer made by an adversary on the assumption that, if one's adversary is proposing a particular set of agreement terms, there is a good chance that those terms are good for the proposer and bad for the recipient. I have called this reaction the "fear of private information" explanation of reactive devaluation, ${ }^{137}$ since its implicit assumption is that devaluation is caused by fear that the proposing party has access to information about the benefits and costs of agreement that the receiving party lacks. (If the recipient of the offer knows all relevant facts concerning the effects of the proposed agreement and both parties' alternatives to reaching a negotiated agreement, there would be no reason for her to fear that the offer contains any informational content that bears on how attractive the proposal is to him.)

134 See generally JACK W. BREHM, A THEORY OF PSychological REACTANCE (1966).

135 Id.

136 See Lee Ross, Reactive Devaluation in Negotiation and Conflict Resolution, in BARRIERS TO CONFLICT RESOLUTION 26, 28 (Kenneth J. Arrow et al. eds., 1995).

137 Korobkin \& Guthrie, supra note 103, at 151. 
In one early reactive devaluation study conducted in the 1980 s, American students rated an arms control proposal lower when it was attributed to Soviet Union leader Mikhail Gorbachev than when it was presented as one of several potential agreements or attributed to American President Ronald Reagan. ${ }^{138}$ An obvious possible explanation for this result is that the subjects realized that they did not know everything there was to know about arms control and, quite rationally, feared that a proposal advanced by the Soviet Union might be harmful to the United States in ways that were not immediately obvious. A study conducted in the mid-1990s might be explained with the same logic. When Jewish Israeli students were asked to evaluate a proposed peace agreement between Israel and the Palestinians, students who were told that Israel advanced the proposal rated it significantly more favorably than did students who were told that it emanated from the Palestinian Authority. ${ }^{139}$

Second, a negotiator with a malevolent utility function might devalue an offer made by an adversary because the implicit acceptability of the proposal to the proposer reduces its value to the recipient. I have called this the "spite" explanation of reactive devaluation, ${ }^{140}$ because the source of the devaluation is the utility gained by preventing the proposer from achieving his goal, not because the offer declines in the affirmative benefits it creates for the recipient once it is made. Spite might also explain the results of the arms control and Middle East reactive devaluation studies. That is, it is possible that subjects devalued offers made by people they viewed as adversaries not because they feared the proposal was less desirable for their side than first meets the eye, but because they viewed the other side with malevolence and interpreted the fact that the adversary made the proposal as evidence that it was desirable to the adversary.

Third, a negotiator might devalue an offer made by an adversary if he views the fact of the offer as a signal that the adversary will be willing to make further concessions. This can be called the "aspiration" explanation of reactive devaluation, because the source of devaluation is an increase in the aspirations of the recipient. In many bargaining situations, convention suggests that negotiators will only make offers that are substantially more favorable than their reservation point, in order to maintain the ability to offer further concessions later. Before proposal $\mathrm{X}$ is made, a negotiator might believe that such a proposal approaches or is even superior to his adversary's

138 See Ross, supra note 136, at 29.

139 Ifat Maoz, et al., Reactive Devaluation of an "Israeli" vs. "Palestinian" Peace Proposal, 46 J. CONFLICT RESOL. 515, 528-29 (2002).

140 Korobkin \& Guthrie, supra note 103 , at 151. 
reservation point and thus view it extremely favorably. When the adversary offers $\mathrm{X}$, however, the negotiator might reevaluate his estimation of the adversary's reservation point, believe that even more desirable deals are achievable, increase his aspiration level, find $\mathrm{X}$ now lies below that level, and evaluate $\mathrm{X}$ less favorably.

Finally, it is possible that negotiators sometimes devalue offers once they are made because achievable states of the world are simply less alluring than the unachievable or the uncertain. I have called this motivational explanation "pure reactive devaluation," 141 because it is based on a pure change in perception on the part of the recipient rather than as an implicit informational signal about the value of the offer to either the proposer or the recipient.

It is difficult to be certain whether pure reactive devaluation actually exists, as one or more of the other motivational hypotheses can plausibly explain most of the experimental evidence of the phenomenon. At least one reactive devaluation experiment strongly suggests that pure reactive devaluation can exist, however, because the other three explanations for the results seem implausible. In that experiment, undergraduate students were asked to assume the persona of an unpaid research assistant for a professor, who subsequently relied heavily on the student's research as the basis of an article that had just been accepted for publication. ${ }^{142}$ Subjects were then advised that the professor might be willing to compensate the student either with a cash payment $(\$ 900)$ or a co-author credit on the article. ${ }^{143}$ Finally, subjects were told that the professor did offer him or her either the cash payment or the byline. ${ }^{144}$ When asked to evaluate the two possibilities, subjects who had been told they were offered the cash rated the byline as more valuable, and students who had been told they were offered the byline rated the cash payment as more valuable. ${ }^{145}$

In this experiment, private information seems an unlikely explanation because the professor's offer cannot plausibly provide any information concerning the relative value of cash versus credit to the student. Spite seems an unlikely explanation because (at least in one version of the experiment ${ }^{146}$ ) the student had no reason to dislike or distrust the professor. Aspiration

141 Id. at $151-52$.

142 See Ross, supra note 136 , at 35-36.

143 Id.

144 Id.

$145 \mathrm{Id}$.

146 In one version of the study, the professor was described as having dealt harshly with the student in the past and having a reputation for exploiting research assistants, while in another version no such negative character information was given. Id. at 36 . 
seems an unlikely explanation because no suggestion was ever made that the student would be able to bargain with the professor over the compensation.

\section{B. Reactive Devaluation as an Impediment to Mediation Success}

For a dispute to settle in mediation, of course, someone must be willing to accept a proposal advanced by someone else. In an extreme case, reactive devaluation could be so severe that neither disputant would be willing to accept any proposal made by the other, such that impasse is unavoidable even when the parties' pre-mediation reservation points imply the existence of a bargaining zone. Reactive devaluation is rarely this severe. In any given mediation, however, it is quite possible that the phenomenon can cause a settlement offer that is marginally inside the bargaining zone before it is advanced to be devalued just enough that it falls marginally outside the bargaining zone after it is made. In such cases - and especially when the bargaining zone is relatively small under the best of circumstances-reactive devaluation can be the difference between mediation success and failure.

As a possible example of reactive devaluation at work, consider the basic facts of one dispute that I mediated: the plaintiff, an individual, sued the defendant, a large entity, in a matter in which defendant's liability was conceded but the appropriate amount of damages were at issue. The parties had a trial date just days away. Through an initial discussion with the plaintiff in a private caucus, I learned that the plaintiff was both angry with the defendant and suspicious of its motives. I was also able to infer the plaintiff's reservation point, at least approximately. The defendant made an offer that I judged to be reasonable given the legal merits of the case, and that I thought probably exceeded the plaintiff's reservation price, but which the plaintiff rejected. During discussions over the next two hours, the defendant made a number of additional offers, each somewhat higher than the last. The plaintiff rejected every offer, each time refusing to provide a counter-offer. Finally, the mediation ended in impasse.

Given the legal merits of the case, the defendant's offers, especially the later ones, seemed quite favorable to the plaintiff. And, although I could not be sure, I believed, based on my initial discussions with the plaintiff, that the defendant's later offers were superior to the plaintiff's pre-mediation reservation point. Yet no settlement was reached.

\section{Possible Mediator Interventions}

The different motivational explanations for reactive devaluation suggest different interventions to prevent mediation failure. This observation 
suggests an obvious problem: even when the mediator suspects that reactive devaluation may present an impediment to settlement, he will rarely be able to divine the precise source of the devaluation behavior. Thus, the mediator will often have to try multiple approaches.

When an offeree devalues an adversary's proposal out of fear of private information or due to an increase in aspiration level, the mediator might be able to mitigate the effect by vouching for the reasonableness of the terms offered. That is, the fear of private information might be reduced if the mediator gives his imprimatur to the fairness of the proposal in light of his understanding and evaluation of the parties' evidence and legal claims. It is possible, of course, that the offeror has private information that both the offeree and the mediator lack, so the mediator's imprimatur is not conclusive proof that the offeree is not ignorant of crucial information and thus vulnerable to exploitation. The mediator's blessing at least reduces the likelihood of this result, however

If the offeree devalues an offer because it causes the offeree to conclude that the offeror has a worse reservation point than previously believed and, thus, increases the offeree's aspiration level, the mediator can mitigate the effect by suggesting that he believes - if he in fact does - that the offer is actually close to the offeror's reservation point. The offeree, who knows that the offeror will often try to mislead the mediator as to her reservation price, is unlikely to place complete confidence in the mediator's estimate. Nonetheless, the mediator's estimate of how close the offer is to the offeror's reservation point is likely to carry some persuasive weight with the offeree, potentially dampening the increase in aspirations that the offer provoked.

Alternatively, the mediator can attempt to preempt reactive devaluation by proposing settlement terms himself. In theory, this intervention should not mitigate pure reactive devaluation, as reactance theory posits that the effect is triggered by the existence of an offer, not its source. A mediator proposal, however, could avoid devaluation that results from spite: if the mediator makes the proposal, there is no reason for either party to think that the offer is viewed as particularly desirable or beneficial by their adversary. In a between-subject experiment simulating a lawsuit settlement negotiation, Chris Guthrie and I found that subjects playing the role of plaintiffs in a personal injury lawsuit were less likely to accept a settlement proposal made by the defendant than by the mediator when subjects were told that the defendant had treated them badly throughout the litigation but were not more likely to accept the offer when proposed by the mediator when they were told that the defendant had treated them extremely politely and respectfully throughout the litigation. ${ }^{147}$ A mediator's settlement proposal might be less

${ }^{147}$ Korobkin \& Guthrie, supra note 103, at 155-60. 
likely to be devalued due to fear of private information as well (although Guthrie and I were unable to demonstrate this effect in the same set of experiments ${ }^{148}$ ), and a proposal emanating from the mediator rather than the adversary is less likely to be devalued on the theory that it signals the adversary will be willing to make further concessions. ${ }^{149}$

Finally, a mediator might reduce the force of any tendency to reactively devalue proposals by eliciting evaluations of possible settlement proposals from both parties prior to allowing either side to actually make any offer. ${ }^{150}$ In other words, the mediator might ask the plaintiff to evaluate hypothetical settlement proposals $\mathrm{A}, \mathrm{B}$, and $\mathrm{C}$ before any offers are placed on the table. If the plaintiff responds that $A$ and $B$ would be unacceptable, but $C$ would be acceptable, it will be difficult for him to later reject an offer of $\mathrm{C}$ even if he feels the urge to devalue it, because doing so would require him to behave inconsistently.

This approach is not without serious risks, however, because a disputant who provides the mediator with false evaluations may unwittingly create unrealistic aspirations. For example, assume the following premises:

(a) before beginning the mediation the plaintiff determines that his reservation point is $\$ 50,000$;

(b) the mediator asks the plaintiff, in private caucus, to evaluate the acceptability of a variety of hypothetical settlement offers that the defendant might potentially be willing to make;

(c) in an effort to "spin" the mediator for his advantage, the plaintiff tells the mediator that an offer of $\$ 50,000$ would be unacceptable and that the minimum acceptable offer would be $\$ 75,000$.

The mediator's efforts might have reduced the risk that reactive devaluation would cause the plaintiff to reject a settlement proposal of $\$ 75,000$. However, having focused attention on $\$ 75,000$, that number could become a reference point to which settlement offers are compared, and the framing effect might now cause the plaintiff to reject a $\$ 50,000$ offer that would, in fact, have been acceptable at the outset of the mediation.

148 Id. at $157-58$.

${ }^{149}$ Cf. Ross \& Ward, supra note 86, at 293-94 (contending that mediator-originated proposals can neutralize attributions that disputants might make to offers proposed by an adversary).

150 See also Ross, supra note 136 , at 39. 


\section{InTERactional Justice: The Second ORder Problem Caused BY DIVERGENT CONSTRUALS}

An important finding of social psychology is that people often care not only about outcomes, but the processes that are utilized to reach outcomes. Of particular relevance is the widespread finding that, holding outcomes (especially undesirable ones) constant, people are significantly more satisfied if they rate as "fair" the process that resulted in that outcome. ${ }^{151}$ One remarkable study in a relevant context found that disputants are significantly more likely to accept an arbitrator's award in a non-binding arbitration (which, because it is non-coercive, is effectively equivalent to a settlement recommendation offered by a mediator) rather than go to court if they judged the arbitration process as "fair," even holding the awards constant. ${ }^{152}$ A sense of fair process is important, it seems, because it helps satisfy the human desires to feel respect and dignity and to feel a sense of control and selfdetermination. ${ }^{153}$ This insight is, in fact, an important part of the argument in favor of a more expansive use of mediation in dispute resolution, as research indicates disputants who engage in mediation report higher levels of satisfaction than those who litigate. ${ }^{154}$

The experienced utility created by the perceived fairness of process can result from either institutional or interactional factors. ${ }^{155}$ The difference between these concepts is illuminated with an example. A store's policy concerning when to give refunds or future discounts to disappointed customers is an institutional factor-it determines the structure according to which outcome determinations are made. Whether the store's clerk who implements the policy is polite or rude to the customers who seek refunds is an interactional factor-it concerns the interpersonal treatment that the

151 See generally E. Allan LIND \& TOM R. TYLER, THE SOCIAL Psychology OF PROCEDURAL JUSTICE 66-76 (Melvin J. Leamer ed., 1988) (surveying research on legal processes).

152 E. Allan Lind et al., Individual and Corporate Dispute Resolution: Using Procedural Fairness as a Decision Heuristic, 38 ADMIN. SCI. Q. 224, 238-241 (1993).

153 Bruno S. Frey et al., Introducing Procedural Utility: Not Only What, But Also How Matters, 160 J. INSTITUTIONAL \& THEORETICAL ECON. 377, 380 (2004).

154 See generally Roselle L. Wissler, The Effectiveness of Court-Connected Dispute Resolution in Civil Cases, 22 Conflict RESOL. Q. 55, 58, 65, 74; (2004) (finding that nearly all studies of mediation report high participant satisfaction with the process).

155 See Robert J. Bies \& Joseph S. Moag, Interactional Justice: Communication Criteria of Fairness, in RESEARCH ON NEGOTIATION IN ORGANIZATIONS 43, 44-45 (Roy J. Lewicki et al. eds., 1986) (distinguishing between procedural faimess and interactional fairness); Frey et al., supra note 153, at 382 (dividing procedural utility into two similar categories). 
customer experiences within the institution. One study that manipulated these precise factors found that both the store's policy and the clerks' behavior affected customers' expressed willingness to make future purchases there and their likelihood of recommending the store to others. ${ }^{156}$ Interestingly, the treatment by the clerk (the interactional factor) had a much larger affect than the leniency of the policy (the institutional factor), even though the interaction had no effect on the material outcome achieved by the customer. 157 Another study found that high perceptions of interactional justice on the part of fired workers reduced their likelihood of filing legal claims against their former employers, holding other factors constant. ${ }^{158}$ Social psychologists have hypothesized that perceptions of interactional injustice create social injuries that can lead to moral outrage and a desire to retaliate. ${ }^{159}$

The institutional characteristics of mediation-party participation, facilitation by a neutral third-party without coercive power, etc.-can affect the parties' perception of fairness, but research on interactional justice suggests that disputants' perceptions of their interaction with their adversaries during mediation is also important. Specifically, a disputant's perception of how his adversary treats him during the mediation process will often affect his willingness to agree to specific settlements and, therefore, the effective breadth of the bargaining zone. When a disputant believes he has been treated with respect, dignity, and honesty by his adversary and feels he is able to exercise some degree of agency in reaching settlement terms, he is

156 Jeffrey G. Blodgett et al., The Effects of Distributive, Procedural, and Interactional Justice on Postcomplaint Behavior, 73 J. RETAILING 185, 197-200 (1997). The authors manipulated three variables: whether the clerk was polite, courteous, and apologized to the customer; whether the customer was offered a full exchange or only a discount on a future purchase; and whether the manager was or was not immediately available to help the customer. $I d$. at 192 . The authors labeled the first manipulation "interactional justice," the second "distributive justice," and the third "procedural justice." Id. However, I believe that it is the second factor that is procedural in nature. The first and second manipulations had statistically significant effects on subjects' responses, while the third did not. $I d$. at 198.

157 Id. at 199.

158 See Barry M. Goldman, The Application of Referent Cognitions Theory to LegalClaiming by Terminated Workers: The Role of Organizational Justice and Anger, $29 \mathrm{~J}$. MGMT. 705, 720-21 (2003); see also Therese (Tess) Collie et al., Fair Process Revisited: Differential Effects of Interactional and Procedural Justice in the Presence of Social Comparison Information, 38 J. EXPERIMENTAL SOC. PSYCHOL. 545, 552 (2002) (finding interpersonal treatment of customers in service environment had significant effect on customer satisfaction).

159 See Bies, supra note 93, at 293-296. 
likely to perceive higher levels of interactional justice than if he feels these elements are lacking. ${ }^{160}$ If the parties perceive interactionally just treatment, the bargaining zone will be larger and mutually desirable settlement terms will be more likely to exist.

Optimistic overconfidence, attribution biases, framing effects, and reactive devaluation all directly reduce the likelihood of mediation success, for the reasons discussed in the previous sections of this article. But because each of these psychological processes can lead to divergent construals of the same facts by the disputants, they also have the potential to create secondorder impediments to mediation success by fueling a dysfunctional interpersonal dynamic that results in the parties perceiving low levels of interactional justice in their dealings with their adversaries. Worse still, these sources of divergent construals might interact in a way that has a multiplicative effect on perceptions of interactional justice. Consider, for example, the following stylized scenario:

Optimistic overconfidence causes Defendant (D) to believe that the legal merits of Plaintiff's (P) cause of action justifies only a low settlement amount, and he makes an accordingly low settlement offer in mediation. $P$ attributes the fact that $\mathrm{D}$ offered a low amount to disrespect for $\mathrm{P}$ and the injuries that she has suffered, which in turn causes her to determine that $D$ has treated her unfairly. Because D's offer appears particularly low when viewed in juxtaposition to P's much higher aspiration level, which is a result in part of P's optimistic overconfidence, this negative attribution is exacerbated. As a result, $P$ claims that D's offer is a non-starter, and she refuses to make a counterproposal. D attributes the refusal to counter to P's bad faith and lack of serious intent to reach a settlement agreement. His belief that he is the victim of interactionally unfair treatment makes him unwilling to increase his offer. He tells $P$ that he will not "bid against himself."

In a lengthy caucus, the mediator persuades a grudging $P$ to make a counter-offer in an effort to demonstrate her good-faith interest in settlement. Still believing that D's offer was disrespectful, however, $P$ makes an extremely high counteroffer. Each party now views his or her proposal as a

160 Cf. E. Allan Lind, Social Involvement, Justice Judgments, and the Psychology of Negotiation, in 7 RESEARCH ON NEGOTLATION IN ORGANIZATIONS 125, 127 (Robert J. Bies et al. eds., 1999) (finding that whether fired employees sued their employer depended more on whether they believed they had been treated with dignity and honesty than their prediction of the expected value of litigation); Daniel P. Skarlicki \& Robert Folger, Retaliation in the Workplace: The Roles of Distributive, Procedural, and Interactional Justice, 82 J. APPLIED PSYCHOL. 434, 438 (1997) (finding workers less likely to retaliate against employers for perceived substantive or procedural unfaimess when they perceive high levels of interactional justice). 
reference point, from which any concessions appear to be losses rather than accommodations necessary to achieve the gains of out-of-court settlement. Because of this, D makes a counteroffer, but it is somewhat lower than he otherwise might have proposed had he not experienced making the proposal as suffering a loss. The proposal might have been acceptable to $P$ under different circumstances, but his perception of being treated unfairly and disrespectfully by D causes him to devalue the proposal, both because he now loathes the idea of agreeing to terms that $\mathrm{D}$ would obviously find acceptable and because he distrusts D's motives-perhaps D has reason to know that his case will not hold up as well in court as his lawyer claims to believe. $P$ rejects the offer.

This scenario illustrates how divergent construals of a variety of disputerelated facts on the part of the disputants-concerning the legal merits of the dispute, the disposition of the opposing party, or the offers made-can create impediments to mediation success not only directly, but also indirectly through the effect that they have on disputant perceptions of interactional justice. The ability of a mediator to minimize divergent construals is thus doubly valuable.

\section{CONCLUSION: NORMATIVE IMPLICATIONS FOR MEDIATOR ORIENTATIONS}

This article has combined descriptions of psychological biasesoptimistic overconfidence, attribution biases, framing effects, and reactive devaluation - that can create impediments to mediation success (both directly and indirectly through their impact on perceptions of interactional justice) with prescriptions for how mediators might attempt to mitigate these impediments. Implicit in this discussion, however, there is also a normative view of efficacious mediation practice. This implicit view bears at least a brief explicit discussion.

Among students of mediation, there is a split in opinion on the question of the proper role of the mediator. According to one view, often labeled "facilitative," mediators should remain somewhat aloof and detached from the content of the dispute, facilitating discussion between the parties but being careful to leave to the parties the task of fashioning a resolution of the dispute. ${ }^{161}$ Proponents of this view emphasize the value of party autonomy,

161 See Leonard L. Riskin, Understanding Mediators' Orientations, Strategies, and Techniques: A Grid for the Perplexed, 1 HARV. NeGOT. L. REV. 7, 9 (1996); see also Nancy Erbe, The Global Popularity and Promise of Facilitative ADR, 18 TEMP. INT'L \& CoMP. L.J. 343, 356 (2004); Murray S. Levin, The Propriety of Evaluative Mediation: 
self-determination, and responsibility. ${ }^{162}$ To maximize the satisfaction of these values, the mediator should help structure a process for communication and problem solving, but the parties must bear the laboring in oar in reaching a resolution of their dispute. ${ }^{163}$ In the alternative view, sometimes called "evaluative," the mediator takes a more active role in resolving the dispute, not only facilitating communication between the parties but offering judgments about the dispute and perhaps substantive suggestions concerning resolutions, guiding them with a firm-although not coercive-hand towards settlement, at least in cases in which the mediator believes a bargaining zone exists. 164

The experimental evidence concerning psychological impediments to mediation success and my experience attempting to overcome these impediments in the mediation process lead to prescriptive advice in this article that implicitly adopts the latter, more intrusive mediation approach. Despite the philosophical merits of the facilitative vision of mediation, and some evidence that disputants might prefer this approach in the abstract, ${ }^{165} \mathrm{I}$

Concerns About the Nature and Quality of an Evaluative Opinion, 16 Онго ST. J. ON DISP. RESOL. 267, 268 (2001); Jeffrey W. Stempel, The Inevitability of the Eclectic: Liberating ADR from Ideology, 2000 J. DISP. RESOL. 247, 251-52; Joseph B. Stulberg, Facilitative Versus Evaluative Mediator Orientations: Piercing the "Grid" Lock, 24 FLA. ST. U. L. REV. 985, 987-989 (1997).

162 See Carole J. Brown, Facilitative Mediation: The Classic Approach Retains its Appeal, 4 PePP. DisP. ReSOL. L.J. 279, 283 (2004); Kimberlee K. Kovach \& Lela P. Love, "Evaluative" Mediation is an Oxymoron, 14 ALTERNATIVES TO HIGH COSTS LITIG. 31, 31 (1996); Lela P. Love, The Top Ten Reasons Why Mediators Should Not Evaluate, 24 FLA. ST. U. L. REV. 937, 939 (1997); Stulberg, supra note 161, at 988; Ellen A. Waldman, The Evaluative-Facilitative Debate in Mediation: Applying the Lens of Therapeutic Jurisprudence, 82 MARQ. L. REV. 155, 164 (1998).

163 See Erbe, supra note 161, at 346; Kovach \& Love, supra note 162, at 31; Levin, supra note 161 , at 268 ; Love, supra note 162 , at 939 ; Riskin, supra note 161 , at 24 ; Stulberg, supra note 161, at 989-990; Zena Zumeta, A Facilitative Mediator Responds, 2000 J. DisP. Resol. 335, 338. See generally Robert A. Baruch Bush, The Dilemmas of Mediation Practice: A Study of Ethical Dilemmas and Policy Implications, 1994 J. DISP. RESOL. 1.

164 See Riskin, supra note 161 , at 9; see also Erbe, supra note 161, at 356; Levin, supra note 161, at 269; Stempel, supra note 161, at 252; Stulberg, supra note 161, at 986-88.

165 In an interesting study, Donna Shestowsky found that student subjects playing the role of disputant in hypothetical scenarios said they would prefer a dispute resolution procedure in which a neutral would help the parties to resolve their dispute to a procedure in which a neutral would propose a resolution that the parties could then accept or veto. Donna Shestowsky, Procedural Preferences in Alternative Dispute Resolution: A Closer, Modern Look at an Old Idea, 10 PsYCHOL. PUB. POL'Y \& L. 211, 231-33 (2004). The author concluded from this "facilitative mediation is preferred to evaluative mediation." 
believe that a mediator's active participation, active insertion of himself in the conflict, and active guidance of the parties toward agreement if a bargaining zone exists is critical to overcoming psychological impediments to settlement in cases in which settlement equates with success. These impediments are often the reason that parties are not able to reach a settlement on their own and thus turn to mediation. Simply put, a mediator who limits his involvement to pure facilitation reduces the number of tools at his disposal that can help the disputants to identify and agree on a set of settlement terms that are more desirable to both parties than adjudication, with its attendant costs and risks.

Id. at 245-46. However, it is not entirely clear that the preference for neutral assistance over neutral direction demonstrates that the subjects were opposed to the concept of evaluation. 
